\title{
Induced polarization response of porous media with metallic particles - Part 9: Influence of permafrost
}

\author{
André Revil ${ }^{1}$, Mridul Razdan ${ }^{2}$, Stéphane Julien ${ }^{3}$, Antoine Coperey ${ }^{3}$, Feras Abdulsamad ${ }^{3}$, \\ Ahmad Ghorbani ${ }^{4}$, Dominique Gasquet ${ }^{2}$, Ravi Sharma ${ }^{2}$, and Magali Rossi ${ }^{5}$
}

\begin{abstract}
We consider a mixture made of dispersed metallic particles immersed into a background material saturated by an electrolyte. Below the freezing temperature (typically $0^{\circ} \mathrm{C}$ to $-4^{\circ} \mathrm{C}$ ), a fraction of the liquid water in the pore space is transformed into ice, whereas the salt remains segregated into the liquid-pore water solution. Our goal is to understand how freezing affects the complex conductivity (induced polarization) of such mixtures. Complex conductivity measurements ( 96 spectra) are performed in a temperature-controlled bath equipped with a high-precision impedance meter. We cover the temperature range from $+20^{\circ} \mathrm{C}$ to $-15^{\circ} \mathrm{C}$ to $-18^{\circ} \mathrm{C}$ and the frequency range from $10^{-2} \mathrm{~Hz}$ to $45 \mathrm{kHz}$. The spectra are fitted with a double Cole-Cole complex conductivity model. A finite-element model is used to further analyze the mechanisms of polarization by considering an intragrain polarization mechanism for the
\end{abstract}

metallic particles and a change of the conductivity of the background material modeled with an exponential freezing curve. This curve is used to relate the liquid water content to the temperature. In the context of freezing, we test all the aspects of the intragrain polarization model developed in the previous papers of this series, at least for a weakly polarizable background material. The Cole-Cole exponent and the chargeability are observed to be essentially independent of temperature including in freezing conditions. This means that all the relaxation times of the system follow the same temperature dependence and that the chargeability is controlled by the volume fraction of metal. The instantaneous conductivity (high-frequency conductivity) and the relaxation times depend on the temperature in a predictable way, and their product can be considered to be essentially temperature independent. The analytical and numerical models can reproduce the inverse relationship between the relaxation time and the instantaneous conductivity.

\section{INTRODUCTION}

Since its first quantitative study by Schlumberger (1920), induced polarization (IP) has emerged as the main geophysical technique used in mineral exploration to localize ore bodies. Therefore, it is not surprising that a vast literature has been devoted to understand the underlying physics behind this method (e.g., Pelton et al., 1978; Mahan et al., 1986; Chu and Bazant, 2006; Flekkøy, 2013). Addi- tionally, tomographic methods have been developed to better image ore bodies. IP for ore localization is currently routinely performed on the subsurface of the earth (Liu et al., 2017) and also below the seafloor (Veeken et al., 2009). The IP method also has various applications in environmental studies from groundwater resource assessment to monitoring of the fate of organic and inorganic contaminants (e.g., Vaudelet et al., 2011; Kemna et al., 2012; Revil et al., 2012; Abdel Aal et al., 2014).

Manuscript received by the Editor 16 January 2019; revised manuscript received 8 May 2019; published ahead of production 03 July 2019 ; published online 13 September 2019

${ }^{1}$ Université Grenoble Alpes, Université Savoie Mont Blanc, CNRS, IRD, IFSTTAR, ISTerre, Grenoble 38000, France and Université de Savoie Mont-Blanc, Laboratoire EDYTEM, UMR 5204 du CNRS, Campus Scientifique, F-73376 Le Bourget-du-Lac, Chambéry, France. E-mail: andre.revil@univ-smb.fr (corresponding author)

${ }^{2}$ Indian Institute of Technology Roorkee, Roorkee, India. E-mail: mridulraz@gmail.com; dominique.gasquet@univ-savoie.fr; ravisharmafes@gmail.com.

${ }^{3}$ Université Grenoble Alpes, Université Savoie Mont Blanc, CNRS, IRD, IFSTTAR, ISTerre, Grenoble 38000, France. E-mail: stephane.julien@etu. univ-orleans.fr; antoine.coperey@gmail.com; feras.abdul-samad@univ-smb.fr.

${ }^{4}$ Yazd University, Department of Mining and Metallurgical Engineering, Yazd, Iran. E-mail: ah.ghorbani@yahoo.fr.

${ }^{5}$ Université de Savoie Mont-Blanc, Laboratoire EDYTEM, UMR 5204 du CNRS, Campus Scientifique, F-73376 Le Bourget-du-Lac, Chambéry, France. E-mail: magali.rossi@univ-smb.fr.

(C) 2019 Society of Exploration Geophysicists. All rights reserved. 
In the previous papers of this series, we developed an IP model in which metallic grains (in a broad sense, i.e., including metals such as copper, semiconductors such as pyrite and magnetite, and semimetals such as graphite) are embedded into a porous matrix formed by the insulating mineral grains coated by their electrical double layers with a pore space saturated by a liquid water solution (Revil et al., 2015a, 2015b, 2017a, 2017b; Mao et al., 2016; Misra et al., 2016a, 2016b). The polarization concept of the metallic grains is based on a recently developed intragrain polarization mechanism described by Revil et al. (2015a, 2015b), which is vastly different from the polarization models reported in the literature (see Wong, 1979; Wong and Strangway, 1981; Chu and Bazant, 2006; or even the electrode-type polarization mechanisms described in Börner et al., 2018). In our model, the polarization of the metallic grains is the result of the accumulation/depletion of the charge carriers inside the metallic particles themselves because of their finite dimensions. Past studies focused on the electrical double layer concepts associated with the external surface of the metallic grains and redox processes through this electrical double layer. Another feature of our approach is that the metallic grains are immersed in a polarizable background. This background polarization model is based on the dynamic Stern layer model, the Stern layer being the inner part of the electrical double layer coating the grains (e.g., Rosen and
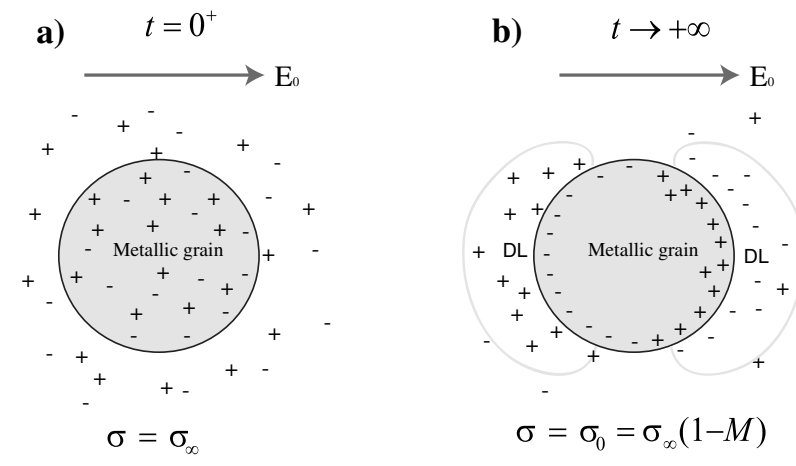

c) $\tau_{i}>>t>>\tau_{e}$

No external field

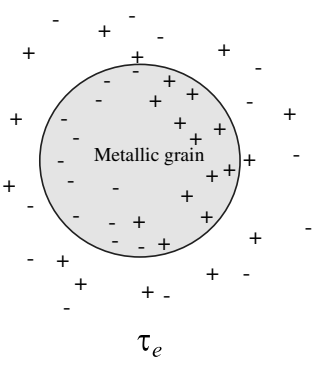

d) $t>\tau_{e}, \tau_{i}$ No external field

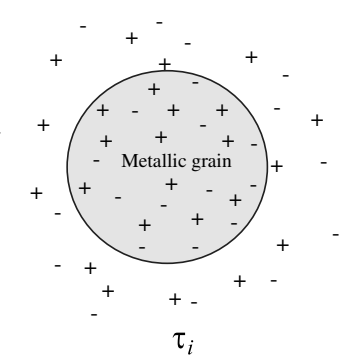

Figure 1. Double polarization mechanism of a metallic particle. (a) After the application of an electrical field $\mathbf{E}_{0}$, all of the charge carriers (electrons and p-holes in the metallic particle and cations and anions in the pore water) are mobile. This defines the instantaneous conductivity $\sigma_{\infty}$. The metallic particle is highly conductive. (b) For a very long application of $\mathbf{E}_{0}$, the metallic particle is polarized and behaves as an insulator. The generated surface charges are responsible for the formation of field-induced electrical DLs in the vicinity of the metallic particle. This situation defines the DC conductivity $\sigma_{0}$. (c) Relaxation of the external charges in the electrolyte with a relaxation time of $\tau_{e}$. (d) Relaxation of the internal charges in the metallic particle with a relaxation time of $\tau_{i}$. There are therefore two relaxation effects.
Saville, 1991). This concept of dynamic Stern layer was first conceptualized in colloidal chemistry by Zukoski and Saville (1986a, 1986b) and developed in geophysics by Revil et al. (2012) and Revil (2013). It implies that the hydrated counterions populating this layer are mobile under the action of an applied electrical field. This concept has been used to model the low-frequency complex conductivity/dielectric spectroscopy of colloidal suspensions by Rosen and Saville (1991) and Leroy et al. (2008).

Now that a quite general polarization model has been established, our goal is to test this model in more extreme conditions (see Revil et al., 2018). We see at least three reasons to investigate the IP of rocks and soils with metallic particles in freezing conditions. (1) This subject is terra incognita. Indeed, to the best of our knowledge, we have not been able to find any quantitative work in this direction. Earlier papers regarding the complex conductivity of porous media without metallic particles in freezing conditions (e.g., Parkhomenko, 1967; Melnikov et al., 1971; Sidorova and Fridrikhsberg, 1973; Snegirev et al., 1973) were based on the mechanism of membrane polarization. However, the underlying physics based on the gradient of the Hittorf numbers through the pore space (Marshall and Madden, 1959) is not able to explain the observed complex conductivity spectra. Indeed, at high salinity, the gradient of the local Hittorf numbers through the pore space is expected to vanish, and the normalized chargeability and quadrature conductivity should go to zero. The data show that the normalized chargeability and quadrature conductivity increase with the salinity in agreement with the Stern layer polarization model (Revil and Florsch, 2010). (2) Valuable mineral resources can be hosted in permafrost, and, currently, IP is still the main method to locate ore bodies. Therefore, a better understanding of how spectral IP can be interpreted in permafrost is valuable to the mining industry. (3) By looking at more extreme conditions than we did so far in our previous papers, we can further test the heuristic aspects of our model

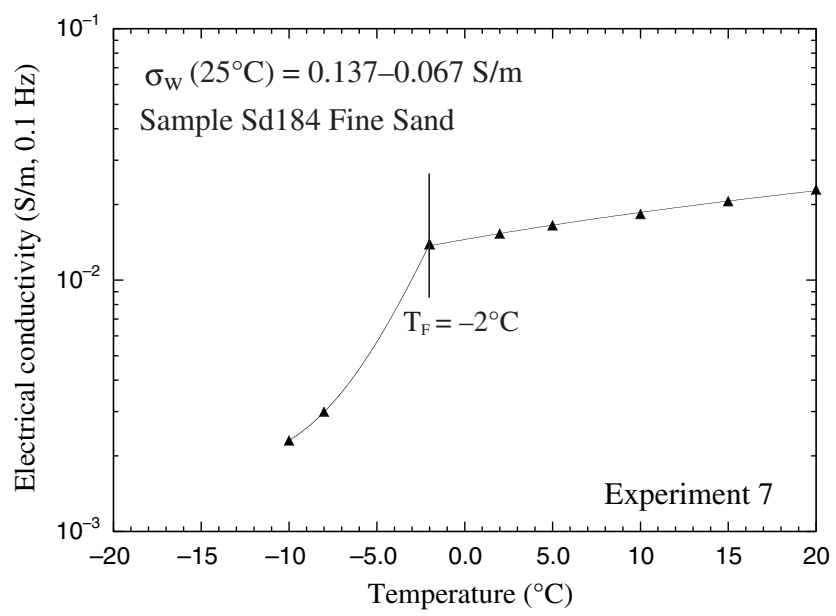

Figure 2. Evolution of the electrical conductivity as a function of the temperature $T\left({ }^{\circ} \mathrm{C}\right)$ for the background material (experiment 7 ). Below the freezing temperature, the fit is done with the exponential freezing curve as described earlier. Above the freezing temperature, the data are fitted by the linear relationship corresponding to equation 13. The change of slope through the freezing point is due to the formation of ice in the pore space of the material. The highest value of pore water conductivity corresponds to the value of the pore water used to saturate the sand. The lowest value corresponds to the value measured after $240 \mathrm{~h}$ of experiments including several cycles of freezing and thawing. 
(especially regarding the underlying physics of the relaxation time) and better understand its strengths and potential weaknesses. Indeed, the changing temperature can be used to further assess the underlying mechanisms of IP as discussed in previous publications (e.g., Binley et al., 2010; Zisser et al., 2010).

\section{THEORY AND NUMERICAL MODELING}

\section{Complex conductivity model above the freezing point}

We consider a mixture made of dispersed metallic grains in a background porous material made of (insulating) mineral grains (coated by an electrical double layer) with a pore space initially entirely filled with a liquid electrolyte. For the sake of simplicity, the "mixture" described above is considered to be isotropic. Figure 1 shows that two polarization mechanisms for the metallic particles themselves may coexist in such mixtures. One is associated with the polarization of the metallic particle themselves, and the second one is associated with the formation of field-induced diffuse layers (DLs) around the metallic particle (Figure 1). Revil et al. (2018) show that, for large metallic particles (say $>500 \mu \mathrm{m}$ ), the low-frequency dispersion is associated with the polarization of the metallic particles, whereas the high-frequency dispersion may be due to the field-induced DL polarization. This double polarization can be the basis for the double Cole-Cole polarization model discussed in Appendix A. In this section, we will essentially focus on the low-frequency polarization associated with the polarization of the metallic particles themselves for large metallic grains.

We write the complex conductivity of this mixture as $\sigma *=\sigma^{\prime}+i \sigma^{\prime \prime}$, where $\sigma^{\prime}$ and $\sigma^{\prime \prime}\left(\mathrm{S} \mathrm{m}^{-1}\right)$ represent the in-phase and quadrature components, respectively. These two properties describe the ability of the rock to conduct current and to reversibly store electrical charges, respectively. In addition, to keep things simple, the frequency dependence of the complex conductivity of the mixture is described in this paper by a simple Cole-Cole parametric model (see Cole and Cole, 1941):

$$
\sigma^{*}=\sigma_{\infty}\left(1-\frac{M}{1+\left(i \omega \tau_{0}\right)^{c}}\right),
$$

(or eventually a double Cole-Cole model as described in Appendix A). In equation 1, $c$ (dimensionless) denotes the ColeCole exponent, $\tau_{0}(\mathrm{~s})$ denotes the Cole-Cole relaxation time, $\sigma_{\infty}\left(\mathrm{S} \mathrm{m}^{-1}\right)$ denotes the instantaneous conductivity, and $M=\left(\sigma_{\infty}-\sigma_{0}\right) / \sigma_{\infty}$ denotes the chargeability (dimensionless). It should be noted that equation 1 could easily be replaced by a more general equation valid for any distribution of the metallic grain sizes. The DC conductivity $\sigma_{0}\left(<\sigma_{\infty}\right)$ denotes the conductivity in steady-state conditions. In these conditions, the charges responsible for the polarization are not available for the conduction process (Figure 1). The instantaneous conductivity $\sigma_{\infty}$ denotes the conductivity, when all the charge carriers are mobile (Figure 1). The Cole-Cole exponent $c$ denotes the broadness of the distribution of relaxation times, when decomposed as a sum of Debye functions. It should be noted that the Cole-Cole probability distribution for the relaxation times indeed has a bell shape that looks like a log-normal distribution. Above freez- ing conditions because all the relaxation times are supposed to have the same temperature dependence, $c$ is expected to be temperature independent (Revil et al., 2018).

The chargeability $M$ (dimensionless) entering equation 1 is directly related to the (dimensionless) volume content of metallic particles $\varphi_{m}$ by (see Revil et al., 2015a, 2015b)

$$
M \approx \frac{9}{2} \varphi_{m}+M_{b},
$$

where $M_{b}$ (dimensionless) denotes the chargeability of the background material defined by

$$
M_{b}=\frac{\sigma_{\infty}^{b}-\sigma_{0}^{b}}{\sigma_{\infty}^{b}},
$$

where $\sigma_{b}^{\infty}$ and $\sigma_{b}^{0}$ denote the instantaneous and steady-state conduc-

\begin{tabular}{|c|c|c|}
\hline Parameter & Symbol & Value \\
\hline Formation factor of clean sand & $F$ & $3.7 \pm 0.2$ \\
\hline Mean grain diameter of sand & $d$ & $200 \pm 20 \mu \mathrm{m}$ \\
\hline Porosity of sand & $\varphi_{S d}$ & $0.40 \pm 0.03$ \\
\hline Cementation exponent of sand & $m$ & 1.43 \\
\hline Grain diameter of pyrite & $a$ & $1.4 \pm 0.2 \mathrm{~cm}$ \\
\hline $\begin{array}{l}\text { Grain diameter of graphite } \\
\text { block }\end{array}$ & $a$ & $(9 \pm 0.2) \times(3 \pm 0.2) \mathrm{cm}$ \\
\hline Grain diameter of galena & $a$ & $(5.4 \pm 0.2) \times(2.8 \pm 0.2) \mathrm{cm}$ \\
\hline Grain diameter of magnetite & $a$ & $1 \pm 0.2 \mathrm{~cm}$ \\
\hline Mass density of pyrite & $\rho_{m}$ & $4400 \mathrm{~kg} \mathrm{~m}^{-3}$ \\
\hline Mass density of magnetite & $\rho_{m}$ & $5200 \mathrm{~kg} \mathrm{~m}^{-3}$ \\
\hline Mass density of graphite & $\rho_{m}$ & $2110 \mathrm{~kg} \mathrm{~m}^{-3}$ \\
\hline Mass density of galena & $\rho_{m}$ & $6860 \mathrm{~kg} \mathrm{~m}^{-3}$ \\
\hline
\end{tabular}
tivities of the background (subscript $b$ ) material, respectively. The

Table 1. Properties of the materials that we used.
Table 2. List of the eight experiments performed in the study.

\begin{tabular}{lccccc}
\hline & & & & Temperature & $\sigma_{w}\left(\mathrm{~S} \mathrm{~m}^{-1}\right)$, \\
Experiment & Material & Background & $\varphi_{m}(-)$ & range & $25^{\circ} \mathrm{C}$ \\
\hline 1 & Chalcopyrite & Sand & 0.11 & $+20^{\circ} \mathrm{C}$ to $-18^{\circ} \mathrm{C}$ & 1.42 \\
2 & Galena & Sand & 0.21 & $+20^{\circ} \mathrm{C}$ to $-15^{\circ} \mathrm{C}$ & 0.14 \\
3 & Graphite & Sand & 0.23 & $+20^{\circ} \mathrm{C}$ to $-18^{\circ} \mathrm{C}$ & 0.14 \\
4 & Magnetite & Sand & 0.06 & $+20^{\circ} \mathrm{C}$ to $-18^{\circ} \mathrm{C}$ & 0.14 \\
5 & Graphite-rich soil & None & Unknown $+20^{\circ} \mathrm{C}$ to $-18^{\circ} \mathrm{C}$ & 1.0 \\
6 & Pyrite & Sand & 0.09 & $+20^{\circ} \mathrm{C}$ to $-15^{\circ} \mathrm{C}$ & 0.14 \\
7 & Sand (background) & None & 0.0 & $+20^{\circ} \mathrm{C}$ to $-10^{\circ} \mathrm{C} 0.137-0.067$ \\
8 & Graphitic sandstone & None & Unknown $+20^{\circ} \mathrm{C}$ to $-18^{\circ} \mathrm{C}$ & 0.019
\end{tabular}

Note: The quantity $\varphi_{m}$ denotes the volumetric content of metallic particles in the material (sand included). The block of chalcopyrite is a mixture of pure chalcopyrite and silica. We have determined its grade as $32 \%$ using its mass density. The volume fraction of the block is $35 \%$ in volume, which leads to the total volume fraction of chalcopyrite in experiment 1 to 0.11 . 
infinity and zero subscripts denote high frequency and low frequency, respectively. Equation 2 is valid as long as the volume fraction of metallic particles is smaller than 0.22 and $M \leq 1$. Explicit expressions for the two conductivities $\sigma_{b}^{\infty}$ and $\sigma_{b}^{0}$ are given below. The instantaneous and the steady-state conductivities of the mixture are related to the instantaneous and steady-state conductivities of the background material according to (Revil et al., 2015a)

$$
\begin{gathered}
\sigma_{\infty}=\sigma_{b}^{\infty}\left(1+3 \varphi_{m}+\cdots\right), \\
\sigma_{0}=\sigma_{b}^{0}\left(1-\frac{3}{2} \varphi_{m}+\cdots\right),
\end{gathered}
$$

where $\varphi_{m}$ (dimensionless) denotes the volume fraction of metallic particles in the mixture. The underlying physics of these two
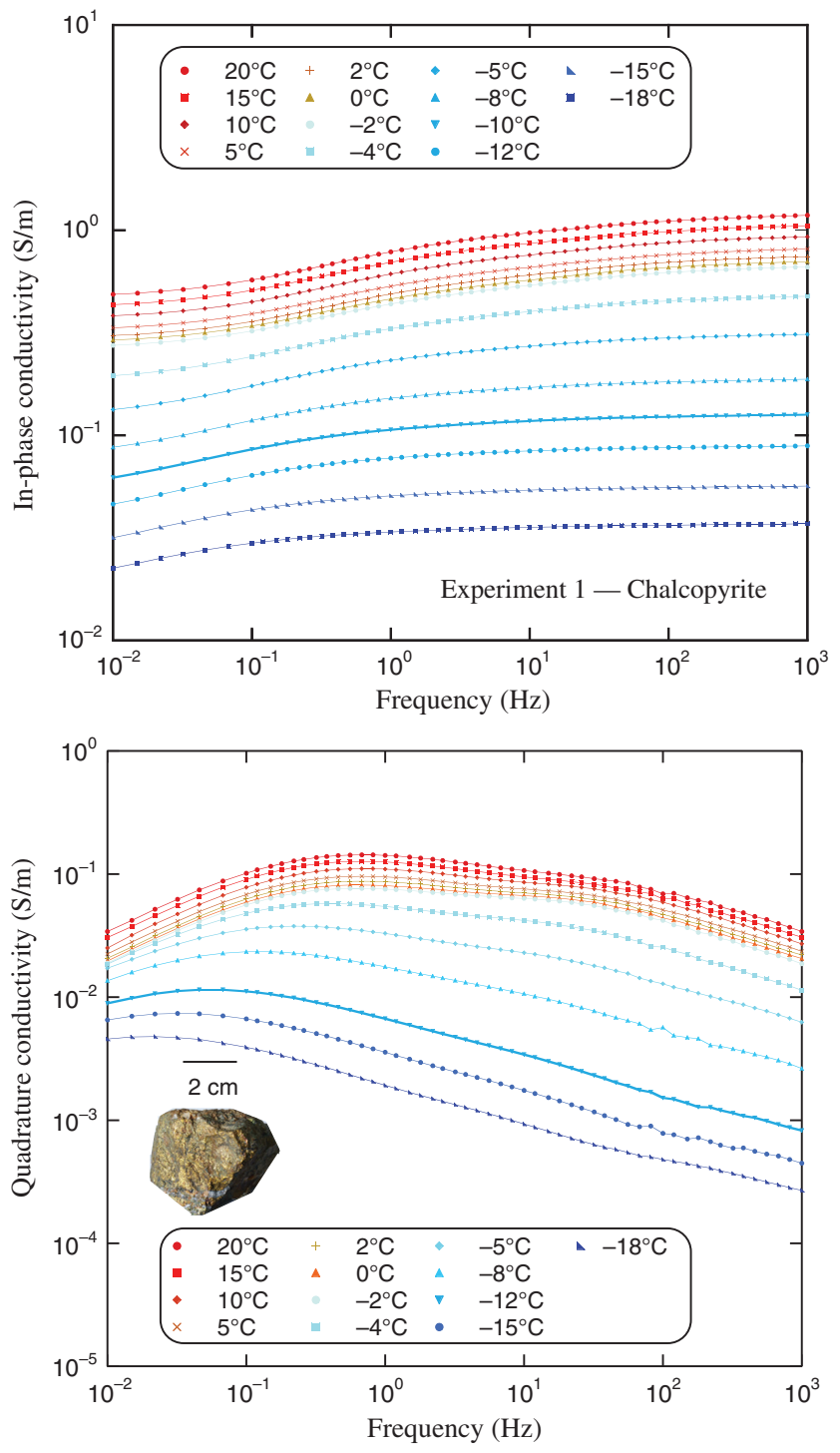

Figure 3. Results of experiment 1 with a block of chalcopyrite immersed in water-saturated sand. The coarse size of the metallic body is consistent with very low frequency at which the mixture polarizes. conductivities is briefly outlined in Figure 1 . The last parameter to investigate is the Cole-Cole relaxation time. In Revil et al. (2018), we inferred that for large metallic particles $(a \gg 500 \mu \mathrm{m})$ the characteristic time constant for the polarization process is given by

$$
\tau_{0}=\frac{a^{2}}{D_{m}}\left(1+\frac{\sigma_{S}^{\infty}}{\sigma_{b}}\right) \approx \frac{a^{2}}{D_{m}} \frac{\sigma_{S}^{\infty}}{\sigma_{b}^{\infty}},
$$

where $D_{m}\left(\mathrm{~m}^{2} \mathrm{~s}^{-1}\right)$ denotes the intrinsic diffusion coefficient of the charge carriers in the metallic particles, $a(\mathrm{~m})$ denotes the radius of the metallic particles, and $\sigma_{S}^{\infty}\left(\mathrm{S} \mathrm{m}^{-1}\right)$ denotes the instantaneous conductivity of the metallic grain. The approximated term (the right-hand side of equation 6) is only valid in the case of $\sigma_{S}^{\infty} / \sigma_{b}^{\infty} \gg 1$, a generally valid assumption. Because $\sigma_{S}^{\infty}$ is expected to be proportional to the diffusion coefficient of the charge carriers, the relaxation time is expected to be independent of the diffusion coefficient of the charge carriers. The mobility of the charge carriers $\left(\beta_{m}\right.$ in $\left.\mathrm{m}^{2} \mathrm{~V}^{-1} \mathrm{~s}^{-1}\right)$ and
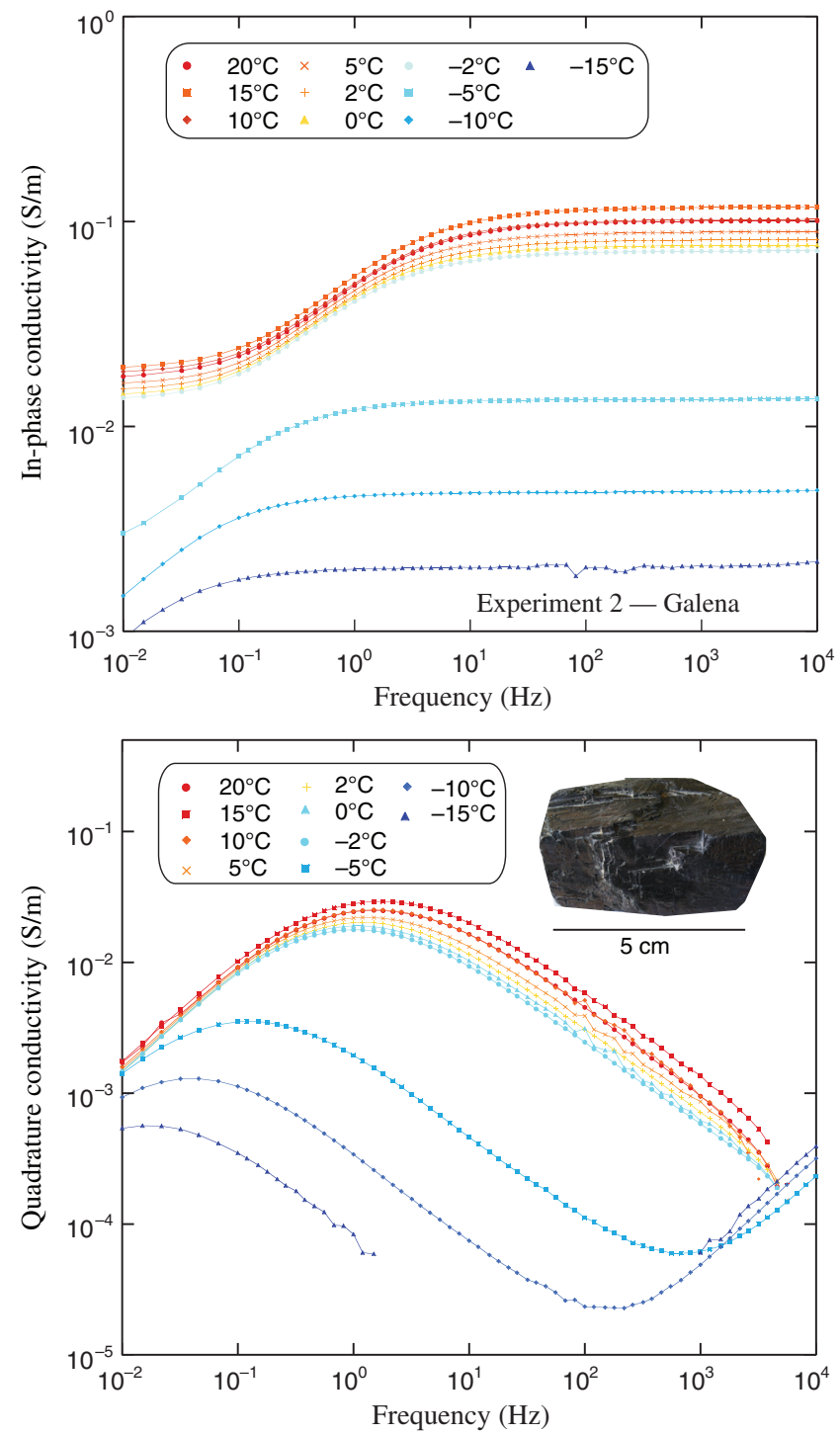

Figure 4. Results of experiment 2 with a piece of pure galena immersed in water-saturated sand. The spectra exhibit a single peak. 
their diffusion coefficient $\left(D_{m}\right.$ in $\left.\mathrm{m}^{2} \mathrm{~s}^{-1}\right)$ are related to each other through the Einstein relationship $D_{m}=\beta_{m} k_{b} T / e$, and the instantaneous conductivity of the particle is given by $\sigma_{S}^{\infty}=e \beta_{m} C_{m}$, where is the Boltzmann constant $\left(1.38 \times 10^{-23} \mathrm{~m}^{2} \mathrm{~kg} \mathrm{~s}^{-2} \mathrm{~K}^{-1}\right), T$ is the absolute temperature $(\mathrm{K}), C_{m}\left(\mathrm{~m}^{-3}\right)$ denotes the concentration of the charge carriers in the solid metallic particle, and $e$ is the elementary charge $\left(1.6 \times 10^{-19} \mathrm{C}\right)$. Combining the equations $D_{m}=\beta_{m} k_{b} T / e$ and $\sigma_{S}^{\infty}=e \beta_{m} C_{m}$ with equation 6 yields the following expression for the relaxation time:

$$
\tau_{0} \approx \frac{a^{2} e^{2} C_{m}}{k_{b} T \sigma_{b}^{\infty}}
$$

For semiconductors, the concentration of the charge carriers is temperature dependent and is given approximately by (e.g., Streetman and Banerjee, 2007, Chapter 3.3)
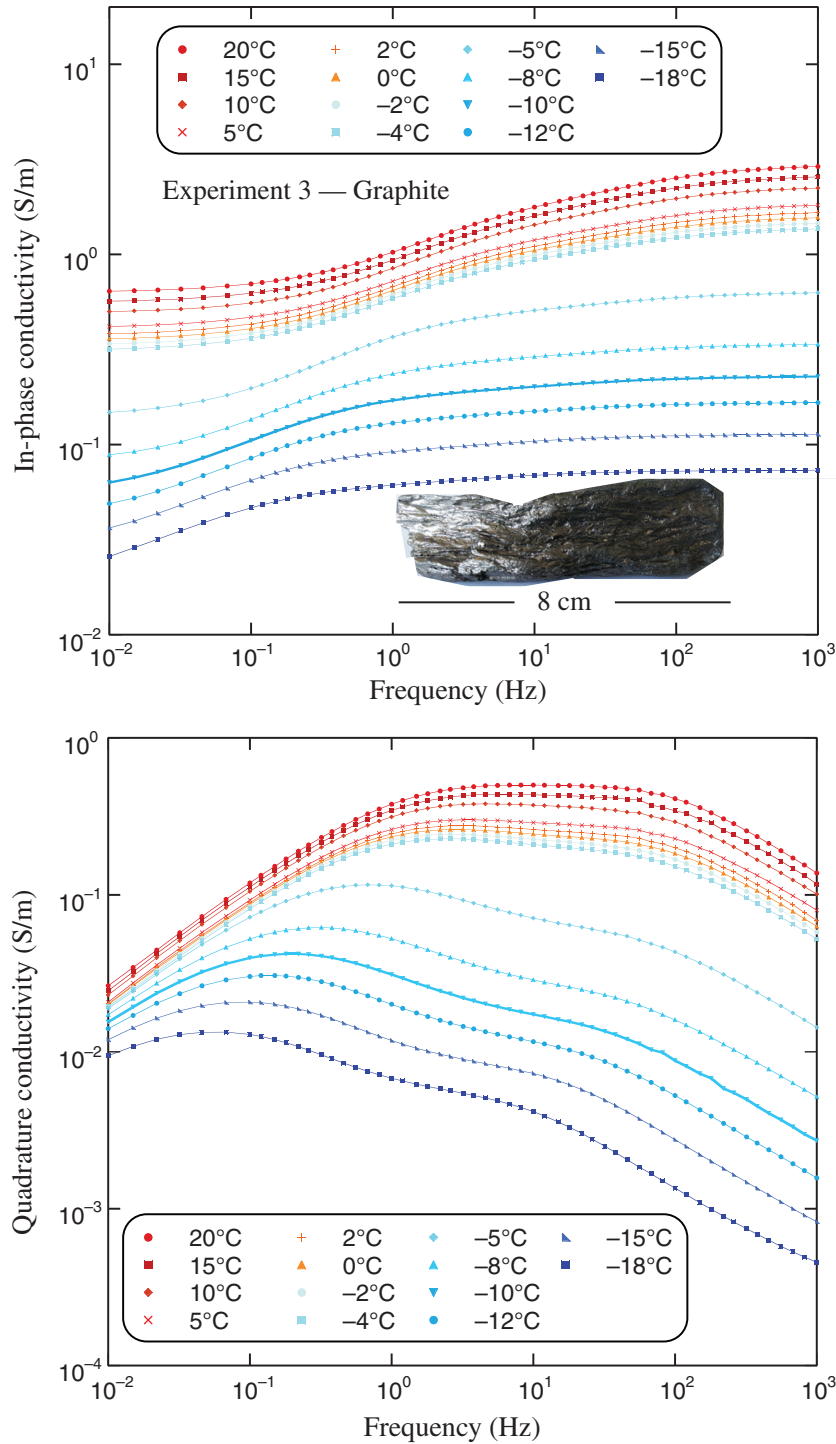

Figure 5. Results of experiment 3 with graphite immersed in watersaturated sand.

$$
C_{m}(T) \approx C_{m}^{0} T \exp \left(-\frac{\Delta E}{R T}\right)
$$

where $\Delta E\left(\mathrm{~kJ} \mathrm{Mol}^{-1}\right)$ denotes the activation energy for the concentration of the charge carriers. Combining equations 7 and 8, the Cole-Cole relaxation time is given as

$$
\tau_{0} \approx \frac{a^{2} e^{2} C_{m}^{0} \exp \left(-\frac{\Delta E}{R T}\right)}{k_{b} \sigma_{b}^{\infty}} .
$$

From equations 8 and 9 , it is clear that the dependence of $\tau_{0}$ on temperature comes from $C_{m}(T)$ and $\sigma_{b}^{\infty}$. For the temperature range considered in the present work, Streetman and Banerjee (2007, Chapter 3.3) show that the temperature dependence of the concentration of the
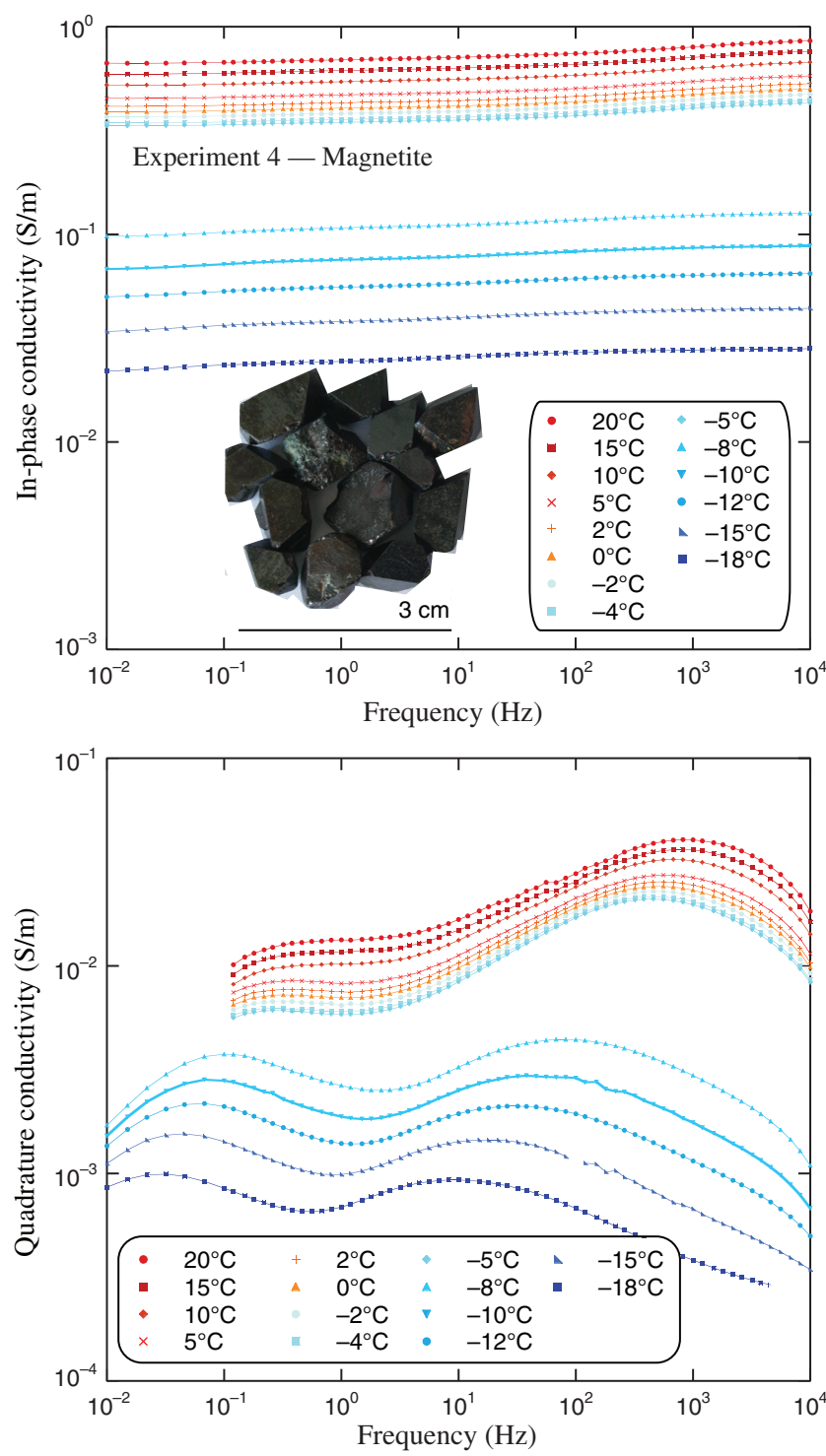

Figure 6. Results of experiment 4 with magnetite crystals immersed in water-saturated sand. Note that the spectra show two distinct peaks. 
charge carriers can be neglected (i.e., $\Delta E$ is small, and so we expect $\tau_{0} \sigma_{b}^{\infty}$ to be essentially temperature independent). We discuss this point below.

\section{Background polarization model above the freezing point}

Revil (2013) obtains the following expressions for the high- and low-frequency conductivities of the background material (i.e., for the instantaneous conductivity and DC conductivity of the background material):

$$
\sigma_{b}^{\infty}=\frac{1}{F} \sigma_{w}+\left(\frac{1}{F \phi}\right) \rho_{g} B \mathrm{CEC},
$$
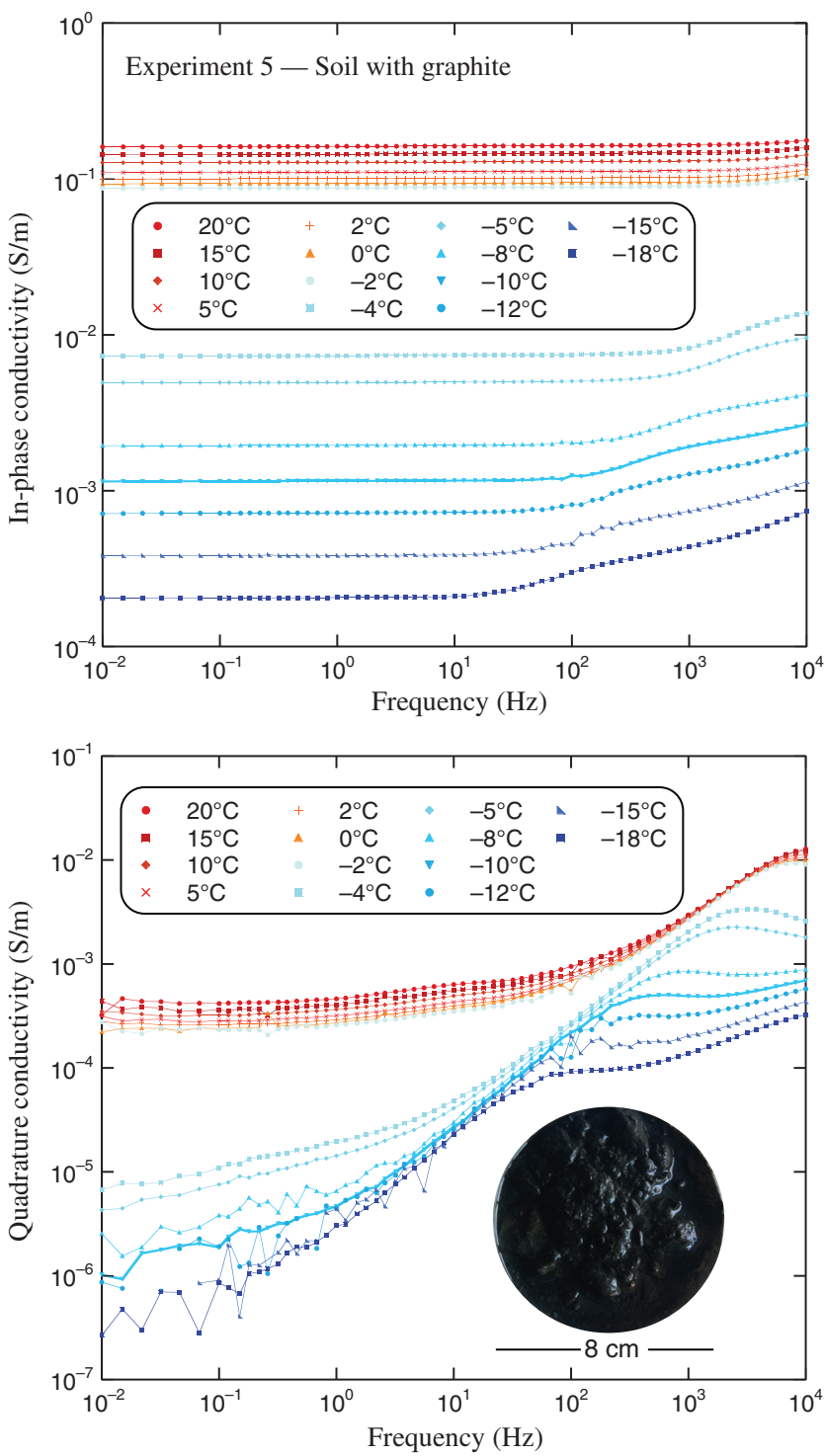

Figure 7. Results of experiment 5 with soil rich in graphite from the ski resort of Val Thorens in the French Alps. This soil lies over graphitic-rich schist formations.

$$
\sigma_{b}^{0}=\frac{1}{F} \sigma_{w}+\left(\frac{1}{F \phi}\right) \rho_{g}(B-\lambda) \mathrm{CEC},
$$

where $\sigma_{w}\left(\mathrm{~S} \mathrm{~m}^{-1}\right)$ is the pore water conductivity (which depends on salinity and temperature), $F$ (dimensionless) is the intrinsic formation factor related to the connected porosity $\varphi$ (dimensionless) by the first Archie's law $F=\phi^{-m}$, where $m$ is called the first Archie exponent or porosity exponent (Archie, 1942), $\rho_{g}$ is the grain density $\left(\mathrm{kg} \mathrm{m}^{-3}\right.$, usually $\left.\rho_{g}=2650 \mathrm{~kg} \mathrm{~m}^{-3}\right)$, and CEC is the cation exchange capacity $\left(\mathrm{C} \mathrm{kg}^{-1}\right.$ and often expressed in meq/100 $\mathrm{g}$ with $\left.1 \mathrm{meq} / 100 \mathrm{~g}=963.20 \mathrm{C} \mathrm{kg}^{-1}\right)$. Equations 10 and 11 clearly show the effect of surface conduction corresponding to the last terms of

\begin{tabular}{|c|c|c|c|c|c|c|c|}
\hline$\left({ }^{\circ} \mathrm{C}\right)$ & $\tau_{1}(\mathrm{~s})$ & $\tau_{2}(\mathrm{~s})$ & $c_{1}(-)$ & $c_{2}(-)$ & $M(-)$ & $\begin{array}{c}\sigma_{\infty} \\
(\mathrm{S} / \mathrm{m}) \\
\end{array}$ & $\begin{array}{l}\mathrm{rms} \\
(\%)\end{array}$ \\
\hline 20 & 0.3308 & 0.00513 & 0.6198 & 0.5005 & 0.625 & 1.221 & 0.06 \\
\hline 15 & 0.3648 & 0.00637 & 0.6308 & 0.4881 & 0.625 & 1.087 & 0.0645 \\
\hline 10 & 0.3189 & 0.00449 & 0.6212 & 0.5339 & 0.620 & 0.956 & 0354 \\
\hline 5 & 0.4110 & 0.00802 & 0.6480 & 0.4938 & 0.622 & 0.838 & 0.0727 \\
\hline 2 & 0.4282 & 0.00940 & 0.6588 & 0.4824 & 0.622 & 0.7724 & 0.0983 \\
\hline 0 & 0.4945 & 0.01273 & 0.6804 & 0.4693 & 0.623 & 0.7280 & 0.0936 \\
\hline-2 & 0.5261 & 0.01414 & 0.6785 & 0.4735 & 0.622 & 0.6846 & 0.09210 \\
\hline-4 & 0.7191 & 0.02113 & 0.6571 & 0.4502 & 0.637 & 0.4917 & 0.0883 \\
\hline-5 & 1.2464 & 0.05360 & 0.6583 & 0.4015 & 0.639 & 0.3211 & 0.0907 \\
\hline 8 & 1.685 & 0.06247 & 0.5896 & 0.3832 & 0.630 & 0.1911 & 0.1458 \\
\hline-10 & 2.445 & 0.17058 & 0.5634 & 0.3452 & 0.641 & 0.1285 & 0.1275 \\
\hline-12 & 3.3657 & 2.7062 & 0.4720 & 0.2124 & 0.721 & 0.0905 & 0.1820 \\
\hline-15 & 6.1286 & 0.36670 & 0.4860 & 0.2102 & 0.700 & 0.0577 & 0.1663 \\
\hline 1 & 113 & 0.03075 & 0.4688 & 0.2321 & 0.729 & 0.0376 & 0.1462 \\
\hline
\end{tabular}

Table 3. Relaxation time for experiment 1 (chalcopyrite).

Note: The Cole-Cole parameters are determined using the double Cole-Cole model described in Appendix A.

Table 4. Relaxation time for experiment 2 (galena).

\begin{tabular}{llllllc}
$T\left({ }^{\circ} \mathrm{C}\right)$ & $\tau_{1}(\mathrm{~s})$ & $c_{1}(-)$ & $c_{2}(-)$ & $M(-)$ & $\sigma_{\infty}(\mathrm{S} / \mathrm{m})$ & $\mathrm{rms}(\%)$ \\
\hline 20 & 0.0876 & 0.711 & 0.55 & 0.869 & 0.12803 & 0.615 \\
15 & 0.0773 & 0.694 & 0.583 & 0.885 & 0.16184 & 0.512 \\
10 & 0.0866 & 0.7 & 0.478 & 0.886 & 0.15017 & 0.498 \\
5 & 0.0984 & 0.691 & 0.548 & 0.883 & 0.13360 & 0.509 \\
2 & 0.106 & 0.693 & 0.444 & 0.881 & 0.11937 & 0.469 \\
0 & 0.118 & 0.688 & 0.558 & 0.878 & 0.10935 & 0.492 \\
-2 & 0.126 & 0.686 & 0.417 & 0.876 & 0.10409 & 0.433 \\
-5 & 1.24 & 0.702 & 0.521 & 0.902 & 0.020441 & 0.233 \\
-10 & 4.08 & 0.71 & 0.681 & 0.923 & 0.0078792 & 0.427 \\
-15 & 8.03 & 0.757 & 0.919 & 0.901 & 0.0039019 & 2.23 \\
\hline
\end{tabular}

Note: The Cole-Cole parameters are determined using a double Cole-Cole function described in Appendix A. We have not reported the second time constant in this table because the second peak is not resolvable. 
these two expressions. The CEC is mainly sensitive to the clay type (e.g., kaolinite, illite, and smectite) and the weight fraction of these clay minerals (Patchett, 1975). In equations 10 and 11, B $\left(\mathrm{m}^{2} \mathrm{~s}^{-1} \mathrm{~V}^{-1}\right)$ denotes the apparent mobility of the counterions for surface conduction and $\lambda\left(\mathrm{m}^{2} \mathrm{~s}^{-1} \mathrm{~V}^{-1}\right)$ denotes the apparent mobility of the counterions for the polarization associated with the quadrature conductivity (see Revil et al., 2017a). A dimensionless number $R$

Table 5. Relaxation time for experiment 3 (graphite).

\begin{tabular}{llllllll}
\hline$T$ & & & & & & & \\
$\left({ }^{\circ} \mathrm{C}\right)$ & $\tau_{1}(\mathrm{~s})$ & $\tau_{2}(\mathrm{~s})$ & $c_{1}(-)$ & $c_{2}(-)$ & $M(-)$ & $(\mathrm{S} / \mathrm{m})$ & $(\%)$ \\
\hline 20 & 0.0658 & 0.00309 & 0.685 & 0.682 & 0.803 & 2.988 & 0.0481 \\
15 & 0.0678 & 0.00288 & 0.686 & 0.692 & 0.792 & 2.636 & 0.0605 \\
10 & 0.0906 & 0.00385 & 0.708 & 0.645 & 0.789 & 2.311 & 0.0593 \\
5 & 0.0980 & 0.00330 & 0.698 & 0.660 & 0.788 & 1.8758 & 0.0718 \\
2 & 0.0924 & 0.00298 & 0.686 & 0.678 & 0.785 & 1.703 & 0.0449 \\
0 & 0.0948 & 0.00303 & 0.681 & 0.685 & 0.781 & 1.604 & 0.0467 \\
-2 & 0.0997 & 0.00306 & 0.680 & 0.678 & 0.782 & 1.497 & 0.0390 \\
-4 & 0.1092 & 0.00344 & 0.680 & 0.665 & 0.781 & 1.397 & 0.0420 \\
-5 & 0.2700 & 0.00452 & 0.686 & 0.645 & 0.781 & 0.637 & 0.0471 \\
-8 & 0.5861 & 0.00739 & 0.677 & 0.608 & 0.785 & 0.339 & 0.0775 \\
-10 & 0.9432 & 0.0103 & 0.683 & 0.625 & 0.775 & 0.229 & 0.0879 \\
-12 & 1.459 & 0.0204 & 0.706 & 0.592 & 0.769 & 0.167 & 0.1286 \\
-15 & 2.129 & 0.0290 & 0.702 & 0.597 & 0.764 & 0.113 & 0.1856 \\
-18 & 3.806 & 0.0745 & 0.685 & 0.549 & 0.757 & 0.0733 & 0.354 \\
\hline
\end{tabular}

Note: The Cole-Cole parameters are determined using a double Cole-Cole function (see Appendix A).

Table 6. Relaxation time for experiment 4 (magnetite).

\begin{tabular}{llllllll}
$T$ & & & & & & $\sigma_{\infty}$ & $\mathrm{rms}$ \\
$\left({ }^{\circ} \mathrm{C}\right)$ & $\tau_{1}(\mathrm{~s})$ & $\tau_{2}(\mathrm{~s})$ & $c_{1}(-)$ & $c_{2}(-)$ & $M(-)$ & $(\mathrm{S} / \mathrm{m})$ & $(\%)$ \\
\hline
\end{tabular}

$\begin{array}{lllllllll}20 & 0.4121 & 0.0002755 & 0.7847 & 0.5030 & 0.2378 & 0.8759 & 0.4290\end{array}$

$\begin{array}{lllllllll}15 & 0.4448 & 0.0002796 & 0.7882 & 0.5252 & 0.2409 & 0.7789 & 0.3976\end{array}$

$\begin{array}{lllllllll}10 & 0.5922 & 0.0003055 & 0.7848 & 0.4855 & 0.2456 & 0.6930 & 0.3912\end{array}$

$\begin{array}{llllllllll}5 & 0.5945 & 0.0003049 & 0.8283 & 0.4841 & 0.2463 & 0.5979 & 0.4183\end{array}$

$\begin{array}{lllllllll}2 & 0.5663 & 0.0003421 & 0.7692 & 0.5261 & 0.2441 & 0.5459 & 0.3305\end{array}$

$\begin{array}{lllllllll}0 & 0.6309 & 0.0003386 & 0.7569 & 0.5003 & 0.2419 & 0.5132 & 0.3499\end{array}$

$\begin{array}{lllllllll}-2 & 0.6998 & 0.0003605 & 0.7740 & 0.5092 & 0.2422 & 0.4834 & 0.2962\end{array}$

$\begin{array}{lllllllll}-4 & 0.7340 & 0.0003464 & 0.7695 & 0.5057 & 0.2431 & 0.4537 & 0.3287\end{array}$

$\begin{array}{lllllllll}-5 & 0.8601 & 0.0003986 & 0.7510 & 0.4800 & 0.2451 & 0.4404 & 0.4223\end{array}$

$\begin{array}{lllllllll}-8 & 1.696 & 0.001692 & 0.8347 & 0.4918 & 0.2393 & 0.1277 & 0.2204\end{array}$

$\begin{array}{lllllllll}-10 & 2.327 & 0.002696 & 0.7976 & 0.4842 & 0.2417 & 0.08925 & 0.1780\end{array}$

$\begin{array}{lllllllll}-12 & 3.425 & 0.003984 & 0.7765 & 0.4529 & 0.2494 & 0.06497 & 0.1932\end{array}$

$\begin{array}{lllllllll}-15 & 4.946 & 0.006974 & 0.7709 & 0.4276 & 0.2527 & 0.04436 & 0.3001\end{array}$

$\begin{array}{lllllllll}-18 & 6.418 & 0.01073 & 0.8101 & 0.4719 & 0.2500 & 0.02817 & 0.2730\end{array}$

Note: The double Cole-Cole parameters are described in Appendix A. is also introduced by $R=\lambda / B$ (for further explanations, see Revil et al., 2017a). From our previous studies (e.g., Ghorbani et al., 2018), we have $B\left(\mathrm{Na}^{+}, 25^{\circ} \mathrm{C}\right)=3.1 \pm 0.3 \times 10^{-9} \mathrm{~m}^{-2} \mathrm{~s}^{-1} \mathrm{~V}^{-1}$ and $\lambda\left(\mathrm{Na}^{+}, 25^{\circ} \mathrm{C}\right)=3.0 \pm 0.7 \times 10^{-10} \mathrm{~m}^{-2} \mathrm{~s}^{-1} \mathrm{~V}^{-1}$, and the dimensionless number $R$ is typically approximately $0.09 \pm 0.01$ (independent of the temperature and saturation). From equations 3,10 , and 11 , the resulting expression of the chargeability of the background is given by

$$
M_{b}=\frac{\rho_{g} \lambda \mathrm{CEC}}{\phi \sigma_{w}+\rho_{g} B \mathrm{CEC}}
$$

showing explicitly the dependence among the background chargeability, the pore water conductivity, and the CEC.

We now discuss the temperature dependence of the complex conductivity above the freezing temperature (typically but not necessarily at approximately $0^{\circ} \mathrm{C}$ ). Following Vinegar and Waxman (1984) and Revil et al. (2017a), the pore water conductivity $\sigma_{w}$ and mobilities $B$ and $\lambda$ have the same linear temperature dependence given by

$$
\Theta(T)=\Theta\left(T_{0}\right)\left[1+\alpha_{T}\left(T-T_{0}\right)\right]
$$

where $T_{0}$ and $T$ are the reference temperature $\left(T_{0}=25^{\circ} \mathrm{C}\right)$ and the temperature $\left({ }^{\circ} \mathrm{C}\right)$, respectively, $\Theta(T)$ corresponds to either $\sigma_{w}(T)$, $B(T)$, or $\lambda(T), \Theta\left(T_{0}\right)$ corresponds to the same property at the reference temperature $T_{0}$, and the sensitivity $\alpha_{T}$ is in the range of $0.019-0.022 /{ }^{\circ} \mathrm{C}$ (e.g., Revil et al., 2018). Equation 13 has been developed as an alternative to the Arrhenius law to determine the effect of the temperature on the mobility of the charge carriers. Because, in a porous medium, liquid pore water exists down to the eutectic temperature, equation 13 still applies down to this temper-

Table 7. Relaxation time for experiment 5 (graphitic-rich soil).

\begin{tabular}{lllllll}
$T$ & & & & & $\begin{array}{c}\sigma_{\infty} \\
(\mathrm{S} / \mathrm{m})\end{array}$ & $\begin{array}{l}\mathrm{rms} \\
(\%)\end{array}$ \\
\hline 20 & $1.65 \mathrm{e}-05$ & 0.996 & 0.0917 & 0.288 & 0.221 & 0.387 \\
15 & $1.5 \mathrm{e}-05$ & 0.959 & 0.0881 & 0.276 & 0.196 & 0.401 \\
10 & $1.05 \mathrm{e}-05$ & 0.894 & 0.0741 & 0.315 & 0.182 & 0.284 \\
5 & $1.74 \mathrm{e}-05$ & 0.964 & 0.0828 & 0.289 & 0.151 & 0.31 \\
2 & $1.76 \mathrm{e}-05$ & 0.954 & 0.091 & 0.263 & 0.134 & 0.29 \\
0 & $1.93 \mathrm{e}-05$ & 0.965 & 0.118 & 0.237 & 0.12 & 0.346 \\
-2 & $2.05 \mathrm{e}-05$ & 0.971 & 0.0984 & 0.249 & 0.114 & 0.412 \\
-4 & $4.14 \mathrm{e}-05$ & 0.944 & 0.19 & 0.541 & 0.0159 & 0.312 \\
-5 & $4.57 \mathrm{e}-05$ & 0.904 & 0.191 & 0.558 & 0.0112 & 0.492 \\
-8 & 0.000179 & 0.893 & 0.813 & 0.664 & 0.00584 & 0.487 \\
-10 & 0.000283 & 0.899 & 0.85 & 0.716 & 0.00411 & 0.418 \\
-12 & 0.000444 & 0.896 & 0.83 & 0.757 & 0.00295 & 0.538 \\
-15 & 0.000652 & 0.895 & 0.917 & 0.772 & 0.00174 & 1.42 \\
-18 & 0.000847 & 0.809 & 0.911 & 0.815 & 0.00112 & 1.22
\end{tabular}

Note: The Cole-Cole parameters are determined using a double Cole-Cole function described in Appendix A. 
ature. In this case, the value of $\alpha_{T}$ can be fixed by the value of the eutectic temperature, i.e., the temperature at which all of the water and salt would crystallize. Indeed, at this temperature, the conductivity of the water is expected to go to zero. The eutectic temperature $T_{E}$ is close to $-21^{\circ} \mathrm{C}$ for $\mathrm{NaCl}$. This value of the eutectic temperature is exactly predicted for $\alpha_{T}=1 /\left(-T_{E}+T_{0}\right)=0.0217 /{ }^{\circ} \mathrm{C}$. In equation 10 , the temperature dependence of the pore water conductivity is controlled by the temperature dependence of the ionic mobilities of the cations and anions.

If the polarization of the background material is weak (e.g., sand), we will consider that its conductivity is given by equation 10 and that the chargeability of this background is much smaller than the chargeability associated with the metallic particles, i.e., $M_{b} \ll(9 / 2) \varphi_{m}$. Therefore, we will neglect this background chargeability below.

Table 8. Relaxation time for experiment 6 (pyrite).

\begin{tabular}{|c|c|c|c|c|c|c|c|}
\hline $\begin{array}{l}T \\
\left({ }^{\circ} \mathrm{C}\right)\end{array}$ & $\tau_{1}(\mathrm{~s})$ & $\tau_{2}(\mathrm{~s})$ & $c_{1}(-)$ & $c_{2}(-)$ & $M(-)$ & $\begin{array}{c}\sigma_{\infty} \\
(\mathrm{S} / \mathrm{m})\end{array}$ & $\begin{array}{l}\mathrm{rms} \\
(\%)\end{array}$ \\
\hline 20 & 0.0681 & $9 e+08$ & 0.059 & 0.58 & 0.00 & & \\
\hline 15 & 0.0622 & - & 0.811 & - & - & & 0 . \\
\hline 10 & 0 & - & 0 & - & - & & 502 \\
\hline 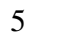 & 0 & $2.2 \mathrm{e}-09$ & & 65 & Q & & 46 \\
\hline 2 & & & & & & & 42 \\
\hline s & & & & & & & 467 \\
\hline-2 & 0 & 4. & 0 & $x^{2}$ & 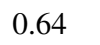 & & 0.386 \\
\hline-5 & 0.589 & $1.73 \mathrm{e}-06$ & 0.802 & 0.0 & 0.729 & & 0.339 \\
\hline-1 & 2.01 & $3.25 \mathrm{e}-06$ & & 0.929 & & & 0.399 \\
\hline-15 & 3.85 & $5.97 \mathrm{e}-06$ & 0.887 & 0.998 & 0.799 & 0.00139 & 2.89 \\
\hline
\end{tabular}

Note: The Cole-Cole parameters are determined using a double Cole-Cole function described in Appendix A.

Table 9. Relaxation time for experiment 8 (graphitic sandstone).

\begin{tabular}{lccccccc}
$\begin{array}{l}T \\
\left({ }^{\circ} \mathrm{C}\right)\end{array}$ & $\tau_{1}(\mathrm{~s})$ & $\tau_{2}(\mathrm{~s})$ & $c_{1}(-)$ & $c_{2}(-)$ & $M(-)$ & \multicolumn{1}{c}{$\begin{array}{c}\sigma_{\infty} \\
(\mathrm{S} / \mathrm{m})\end{array}$} & $\begin{array}{c}\mathrm{rms} \\
(\%)\end{array}$ \\
\hline 20 & 0.054961 & 0.000879 & 0.46509 & 0.84385 & 0.29342 & 0.00019424 & 0.017114 \\
15 & 0.051829 & 0.000856 & 0.45682 & 0.86297 & 0.30064 & 0.00016592 & 0.014612 \\
10 & 0.058884 & 0.000860 & 0.45879 & 0.84266 & 0.30662 & 0.00014181 & 0.012848 \\
5 & 0.059955 & 0.000838 & 0.45704 & 0.8448 & 0.31615 & 0.00011946 & 0.011235 \\
2 & 0.063294 & 0.000833 & 0.4508 & 0.84447 & 0.32226 & 0.00010731 & 0.010211 \\
0 & 0.061448 & 0.000832 & 0.45294 & 0.84615 & 0.32646 & $9.9507 \mathrm{e}-05$ & $9.8300 \mathrm{e}-03$ \\
-2 & 0.060448 & 0.000808 & 0.45289 & 0.8495 & 0.33149 & $9.2355 \mathrm{e}-05$ & $9.2800 \mathrm{e}-03$ \\
-5 & 0.041363 & 0.000656 & 0.45829 & 0.87792 & 0.40098 & $3.9143 \mathrm{e}-05$ & $5.0500 \mathrm{e}-03$ \\
-8 & 0.036761 & 0.000577 & 0.44553 & 0.88877 & 0.46116 & $2.4550 \mathrm{e}-05$ & $3.5300 \mathrm{e}-03$ \\
-10 & 0.03418 & 0.000541 & 0.44304 & 0.89262 & 0.49590 & $1.8909 \mathrm{e}-05$ & $2.8900 \mathrm{e}-03$ \\
-15 & 0.031666 & 0.000487 & 0.43121 & 0.89689 & 0.59170 & $1.0245 \mathrm{e}-05$ & $1.7800 \mathrm{e}-03$
\end{tabular}

Note: The Cole-Cole parameters are determined using a double Cole-Cole function described in Appendix A.

\section{Extension of the background conductivity model in freezing conditions}

In freezing conditions, several effects need to be accounted for. For instance, the mobilities and the pore-water conductivity depend linearly on temperature, and this dependence still holds below the freezing temperature. In addition, the saturation of the liquid pore water solution is expected to change and the salt is expected to remain segregated into the liquid pore water because there is low solubility of the salt in the ice (see Hobbs, 2010). In this paper, we assume that the salt remains totally segregated in the liquid water phase. We write $s_{w}$ (dimensionless) as the saturation ( $s_{w}=1$ at full liquid water saturation) and $\theta$ as the volumetric water content. Therefore, the conductivity of the pore water $\sigma_{w}$ should be replaced by $\sigma_{w} / s_{w}=\sigma_{w} \phi / \theta$ below the freezing temperature to account for the increase in the pore-water salinity when the saturation $s_{w}$ decreases. In this equation, $\theta$ denotes the liquid water content (dimensionless) and $\sigma_{w}$ is the pore water conductivity at saturation (and therefore at the initial salinity and following the temperature dependence corresponding to equation 13) with the brine used initially for saturating the porous material. Only for temperatures lower than the eutectic temperature (approximately $-21^{\circ} \mathrm{C}$ for $\mathrm{NaCl}$ ) are freezing and crystallization for the $\mathrm{NaCl} /$ water system simultaneously achieved in the pore space of the porous material.

At this stage, equations 10 and 11 need to show explicitly the dependence of the different properties with the water content. Assuming that the first and second Archie's exponents of the background material are equal to each other, i.e., $n=m$ (for further discussion, see Revil, 2013) and assuming the segregation of the salt in the liquid water phase, equations 10 and 11 can be written as

$$
\sigma_{b}^{\infty}=\theta^{m-1}\left(\phi \sigma_{w}+\rho_{g} B \mathrm{CEC}\right)
$$

$$
\sigma_{b}^{0}=\theta^{m-1}\left[\phi \sigma_{w}+\rho_{g}(B-\lambda) \mathrm{CEC}\right],
$$

$$
M_{b}=\frac{\rho_{g} \lambda \mathrm{CEC}}{\theta \sigma_{w}+\rho_{g} B \mathrm{CEC}} .
$$

It should be noted that because $\lambda, B$, and $\sigma_{w}$ have the same temperature dependence, the dependence of $M_{b}$ with the temperature comes only from the dependence of the liquid water content $\theta$ on the temperature below the freezing temperature. The instantaneous and DC conductivities of the mixture and its chargeability are related to the (liquid) water content by

$$
\begin{aligned}
\sigma_{\infty} & =\theta^{m-1}\left(\phi \sigma_{w}+\rho_{g} B \mathrm{CEC}\right)\left(1+3 \varphi_{m}\right) \\
\sigma_{0}= & \theta^{m-1}\left(\phi \sigma_{w}+\rho_{g}(B-\lambda) \mathrm{CEC}\right) \\
& \times\left(1-\frac{3}{2} \varphi_{m}\right)
\end{aligned}
$$




$$
M=\frac{9}{2} \varphi_{m}+\frac{\rho_{g} \lambda \mathrm{CEC}}{\theta \sigma_{w}+\rho_{g} B \mathrm{CEC}} .
$$

If the background material is dominated by its bulk pore-water conduction and the background chargeability is small with respect to the chargeability contribution associated with the presence of metallic grains, we can further simplify these equations as

$$
\begin{gathered}
\sigma_{b}=\theta^{m-1} \phi \sigma_{w}, \\
\sigma_{\infty}=\sigma_{b}\left(1+3 \varphi_{m}\right),
\end{gathered}
$$
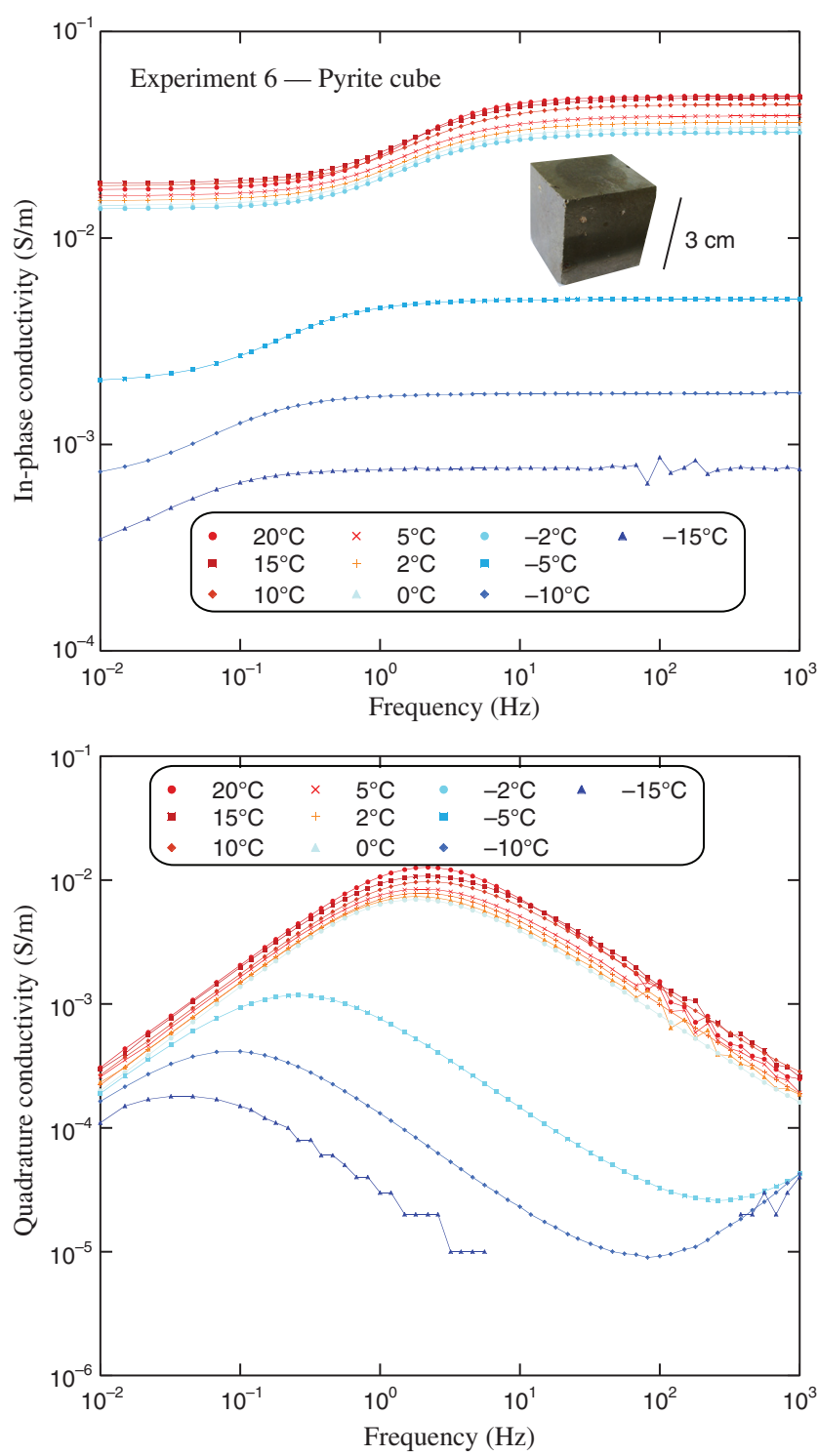

Figure 8. Results of experiment 6 with a pyrite cube immersed in water-saturated sand.

$$
M \approx \frac{9}{2} \varphi_{m},
$$

$$
\tau_{0} \sigma_{b} \approx \frac{a^{2} e^{2} C_{m}^{0}}{k_{b}} \exp \left(-\frac{\Delta E}{R T}\right)
$$

For the experiments reported in the present paper, these assumptions should be obeyed because we used sand as the background material for most of the experiments. Equation 22 indicates that the chargeability should be in the first approximation independent of the temperature. A small second-order effect would be expected because of the dependence of the water content with the temperature in the expression of the background chargeability. Equation 23 indicates that all the relaxation times should have the same temperature dependence
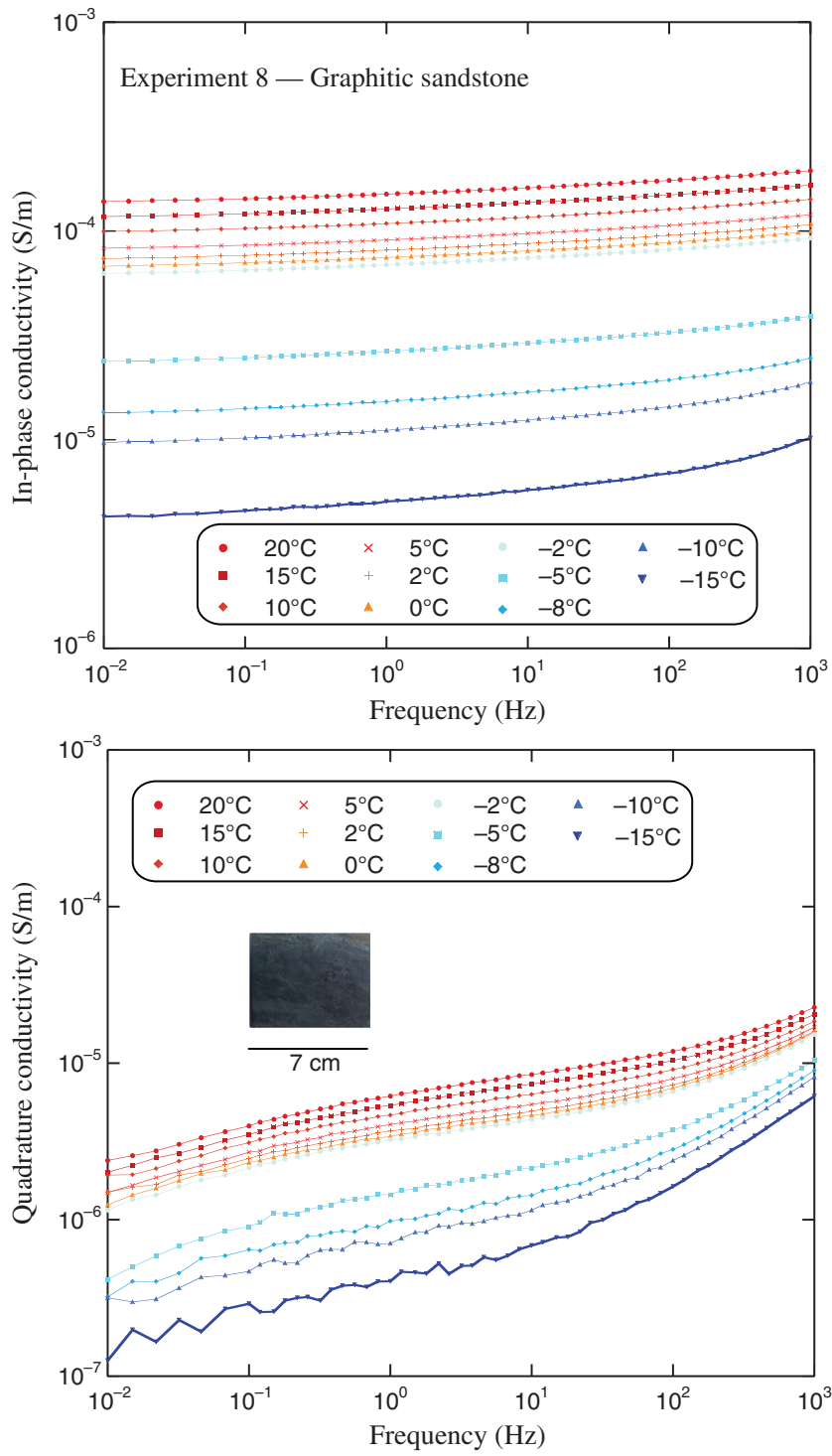

Figure 9. Results of experiment 8 with graphitic sandstone from Val Thorens in the French Alps. We observed rather flat spectra for this sandstone. 
and therefore that the Cole-Cole exponent should be temperature independent. We can further combine equations 20-23 to obtain the following easily testable equations:

$$
\begin{gathered}
\sigma_{\infty}=\theta^{m-1} \phi\left(1+3 \varphi_{m}\right) \sigma_{w}\left(T_{0}\right)\left[1+\alpha_{T}\left(T-T_{0}\right)\right], \\
\tau_{0} \sigma_{\infty} \approx \frac{a^{2} e^{2} C_{m}^{0}}{k_{b}}\left(1+3 \varphi_{m}\right) \exp \left(-\frac{\Delta E}{R T}\right) .
\end{gathered}
$$

The last step of our approach is to connect the water content $\theta$ to the temperature below the freezing point. Below freezing conditions, the water content of the liquid water is gradually changing into ice as the temperature decreases. This change can be described by a so-called freezing curve. Duvillard et al. (2018) use an empirical freezing curve to describe this constitutive law:

$$
\theta(T)=\left\{\begin{array}{ll}
\left(\phi-\theta_{r}\right) \exp \left(-\frac{T-T_{F}}{T_{C}}\right)+\theta_{r}, & T \leq T_{F} \\
\phi, & T>T_{F}
\end{array},\right.
$$

to describe this transition with the temperatures expressed in ${ }^{\circ} \mathrm{C}$. Equation 26 is purely empirical but will be of paramount importance to capture the change of the conductivity trend shown for instance in Figure 2. Because conductivity depends on the liquid water content and the liquid water content depends on temperature, equation 26 offers a bridge to connect electrical conductivity to temperature. In equation $26, \theta_{r}$ denotes the residual water content, when $T \ll T_{F}, T_{F}$ denotes the liquidus or freezing point/temperature, $T_{C}$ denotes a characteristic temperature controlling the transition between the unfrozen state and the frozen state, and $\phi-\theta_{r}$ denotes the maximum volumetric ice content at low temperatures. The residual water content $\theta_{r}$ is dependent on the physicochemical properties of the soil such as specific surface area and the surface charge density (e.g., Anderson and Tice, 1972). Equation 26 supports the hypothesis that the residual water content is formed essentially by a sorbed water film (bound water) at the interface between the ice and the surface of the mineral grains (Dash et al., 1995). The residual pore water disappears at the eutectic temperature. The effect of the initial salt concentration on the freezing temperature $\left(T_{F}\right)$ itself can be determined from the empirical equation proposed by Potter et al. (1978).

Based on a previous model, four predictions can be made, which are tested below in detail against our new experimental data. (1) The Cole-Cole exponent is temperature independent as long as all the relaxation times have the same temperature dependence. A small effect is expected if each relaxation time depends on the water content in each pore and if the liquid water content/temperature relationship depends on the pore size. (2) The chargeability is temperature independent as long as the effect of the background chargeability is negligible. Otherwise, we expect an effect of the temperature on the background chargeability through its dependence with the liquid water content (itself a function of temperature). In our experiments, we expect this effect to be small if not negligible because the amount of metallic particle is large. (3) The product of the instantaneous conductivity of the material (mixture) and the Cole-Cole relaxation time is expected to be weakly dependent on temperature. (4) The instantaneous conductivity of the mixture depends on temperature according to the exponential freezing curve combined with the effect of the temperature on the mobility of the charge carriers.

\section{Numerical modeling}

In addition to the analytical model described above, we performed numerical modeling of the problem by following the procedure of Abdulsamad et al. (2017) to solve the Poisson-Nernst-
Figure 11. Fit (plain line) with the double Cole-Cole complex conductivity model (described in Appendix A) of the complex conductivity data (open circles) for graphite (experiment 3). Note that the double Cole-Cole model perfectly reproduces the data set. (a) In-phase conductivity. (b) Quadrature conductivity. 


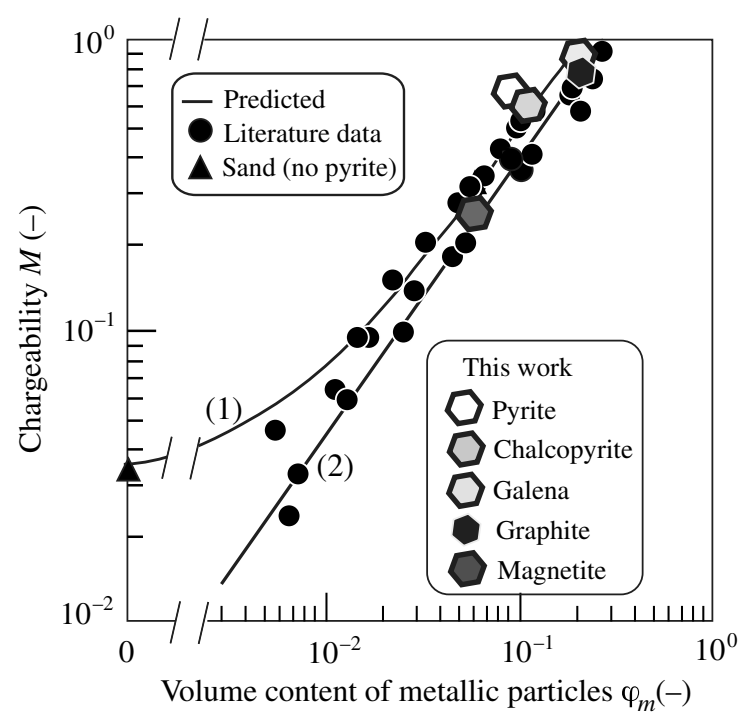

Figure 12 . Chargeability determined as the median of the chargeability data for the whole temperature range and the volume fraction of metallic particles mixed with sand (see Table 2). The two curves are labeled as 1 (with the polarizing background) and 2 (without the polarizing background), respectively (see equation 2 with and without $M_{b}$, respectively). The data from the present paper correspond to chalcopyrite (experiment 1 ), galena (experiment 2 ), graphite (experiment 3), magnetite (experiment 4), and pyrite (experiment 6). The new data correspond to the median values of $M$ for experiments 1-8. Reference data were taken from Pelton et al. (1978), Mahan et al. (1986), Phillips (2010), and Gurin et al. (2015).

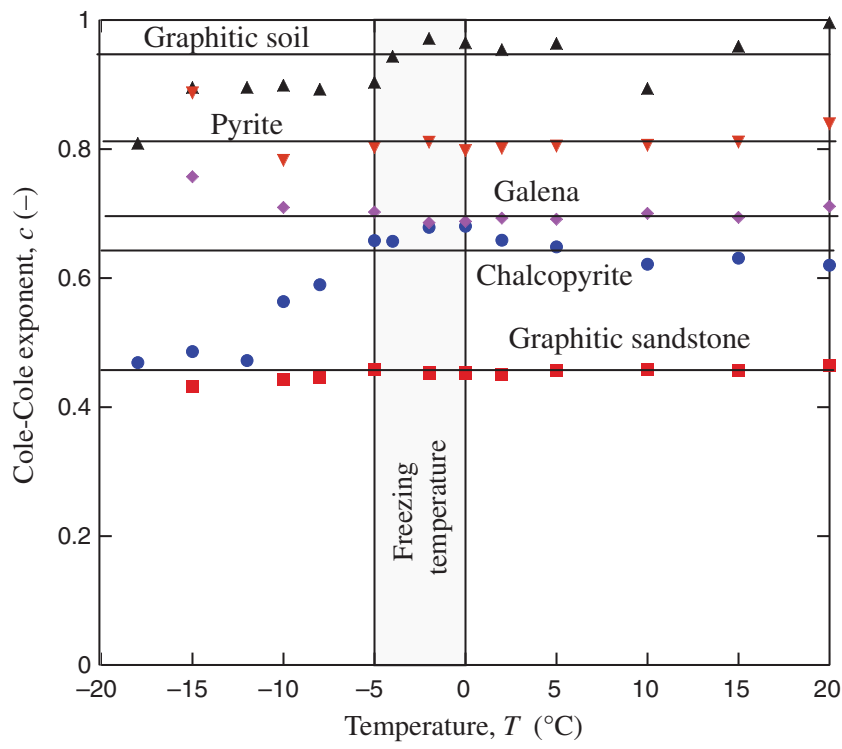

Figure 13. Evolution of the Cole-Cole exponent $c_{1}$ as a function of the temperature for chalcopyrite (experiment 1), graphitic sandstone (experiment 8), galena (experiment 2), graphitic soil (experiment 5), and pyrite (experiment 6 ), all fitted with a double Cole-Cole function as described in Appendix A. The horizontal lines correspond to the mean value of the low-frequency Cole-Cole exponent $c_{1}$ determined above the freezing temperature. For the chalcopyrite and the graphitic soil, we observe a significant decrease in the low-frequency Cole-Cole exponent below the freezing temperature. Otherwise, the Cole-Cole exponent seems to be independent of the temperature.
Planck equations. For these 2D simulations, we considered a metallic particle surrounded by a background material undergoing freezing. The fundamental equations are summarized by Abdulsamad et al. (2017) and Revil et al. (2018) and will not be repeated here. They are solved with the finite-element method. We use equations 20 and 26 to model the effect of the temperature on the background conductivity.

\section{MATERIALS AND METHODS}

\section{Materials}

We use a new collection of eight samples described in Tables 1 and 2 . These samples were chosen to cover a range of metallic particles including semiconductors (pyrite and magnetite), a semimetal (graphite), and a metal (lead with galena). We also considered fine
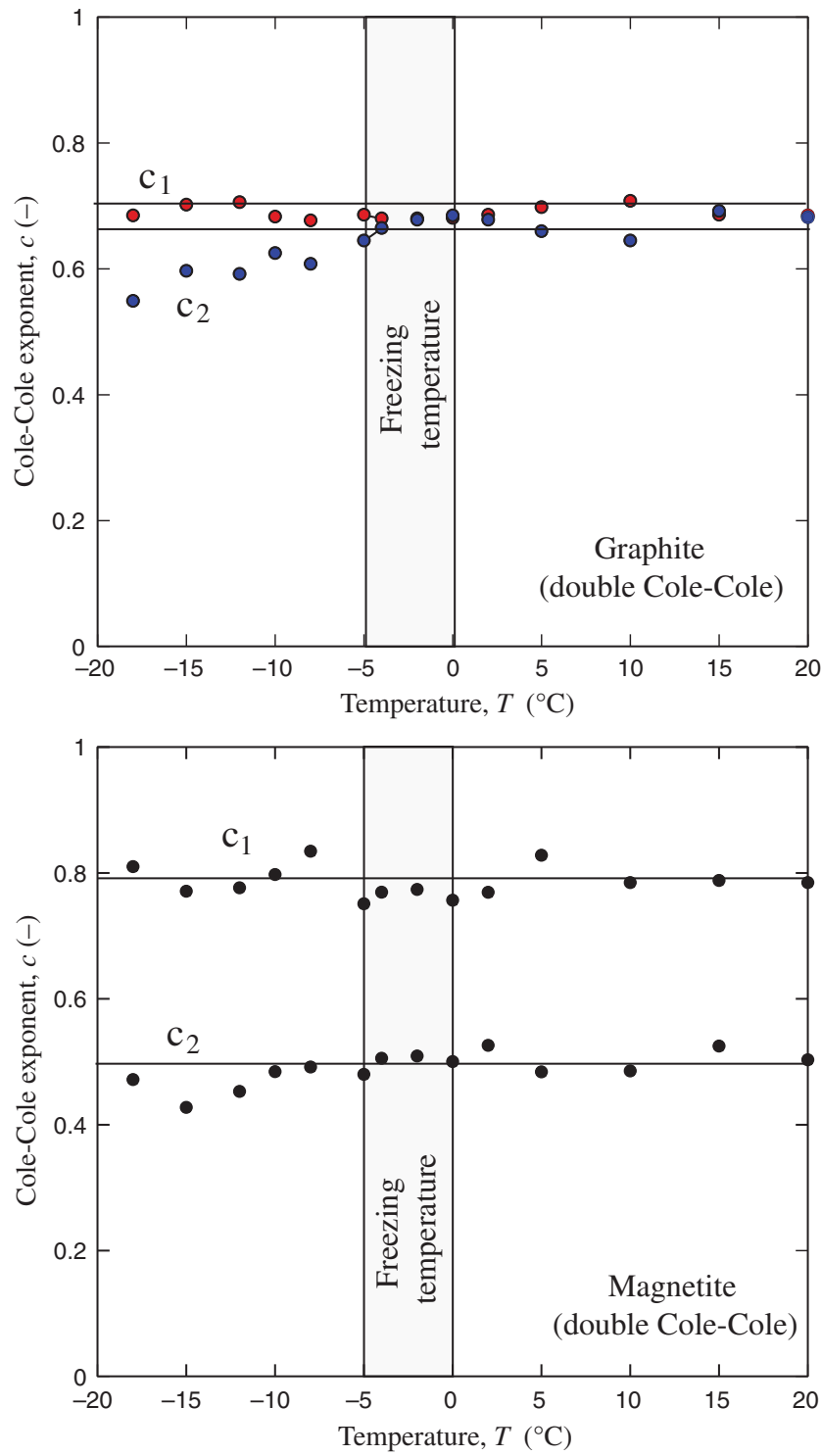

Figure 14. Evolution of the Cole-Cole exponent as a function of the temperature for graphite and magnetite. The Cole-Cole exponents seem to be independent of the temperature. 
and coarse particles that are supposed to polarize at high and low frequencies, respectively. For each sample, we investigated a single salinity; therefore, a total of eight experiments were performed (Table 2) and a total of 94 spectra were obtained.

Five experiments were performed by using sand as the background material (the properties are summarized in Table 1) mixed with either a block of chalcopyrite, galena, graphite, magnetite, or pyrite. Two additional experiments were performed with graphitic soil and graphitic sandstone, both taken at Val Thorens in the French Alps. Finally, one experiment was performed for the sand used as the background in the experiments mentioned above.

\section{Frequency-domain measurements}

The experiments were performed with a temperature-controlled bath (KISS K6, Huber, dimensions $210 \times 400 \times 546 \mathrm{~mm}$, bath volume $4.5 \mathrm{~L}$ ). The spectra were obtained with a ZEL-SIP04-V02 impedance meter (Zimmermann et al., 2007). The frequencydomain measurements were performed from $10 \mathrm{mHz}$ to $45 \mathrm{kHz}$. Because this instrument has been broadly described in our previous papers, we will keep the presentation of the metrological aspects to the minimum level in this paper. Interested readers can find more information in Revil et al. (2017a). The sample holder is a plastic tube with the two current electrodes A and B located at the end faces. The voltage electrodes are located on the side of the sample holder. The conversion of the measured impedance into the complex conductivity was performed using a geometric factor $K\left(\mathrm{~m}^{-1}\right)$ depending on the geometry of the electrodes $\left(K=L / A=36.1 \mathrm{~m}^{-1}\right.$ in the present case, where $A$ is the surface area of a cross section of the cylindrical core sample and $L$ is the distance between the two voltage electrodes $\mathrm{M}$ and $\mathrm{N}$ ). For all of the experiments with the

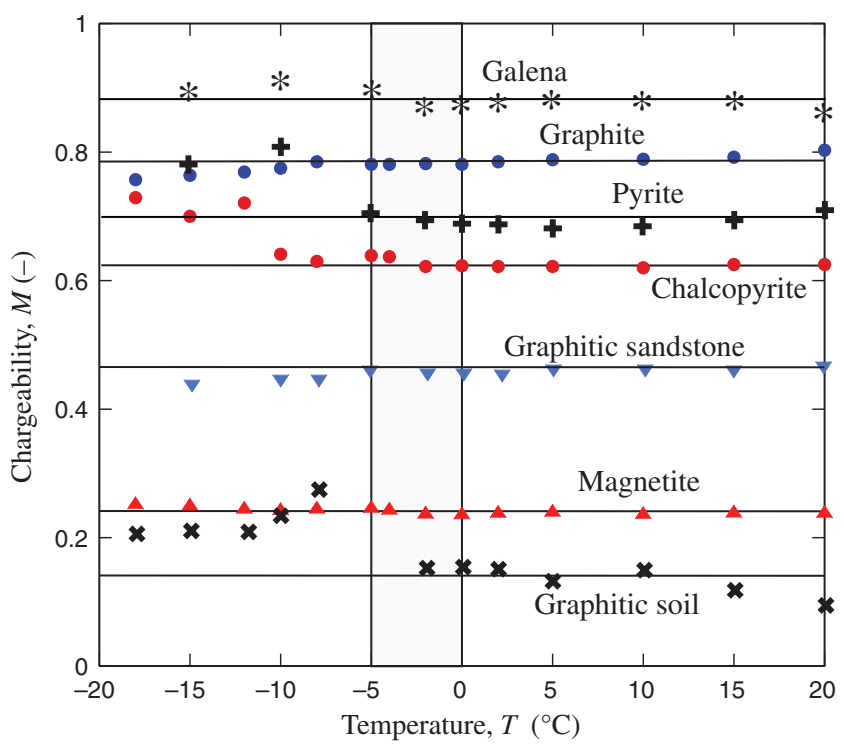

Figure 15. Evolution of the (total) chargeability $M$ as a function of the temperature for chalcopyrite (experiment 1), graphite (experiment 3), and magnetite (experiment 4), all fitted with a double Cole-Cole function described in Appendix A. The horizontal lines are determined from the mean chargeability values above the freezing temperature. exception of graphite, we have a core sample with an inner diameter of $d=4.6 \mathrm{~cm}\left(A=16.6 \mathrm{~cm}^{2}\right)$ and a length of $L=6.0 \mathrm{~cm}$ between $\mathrm{M}$ and $\mathrm{N}$ (for the graphite core sample, we have $d=4.6 \mathrm{~cm}$, $L=8.5 \mathrm{~cm}$, and $K=51.15 \mathrm{~m}^{-1}$ ).

A voltage of $1 \mathrm{~V}$ was applied to the core samples during all of the measurements. The sample holder is placed in a heat-resistant insulating bag, which is itself immersed in the temperature-controlled bath described above. The temperature of this bath is controlled with a precision of approximately $0.1^{\circ} \mathrm{C}$. Glycol is used as the heat carrying fluid. At each temperature, we allow enough time for the system to stabilize in temperature. This stabilization is checked by measuring the temperature over time using a set of thermocouples located in the bath, bag, and on the core sample holder.

The temperature range investigated in the present study is $+20^{\circ} \mathrm{C}$ to $-15^{\circ} \mathrm{C}$, and for some experiments, below $-18^{\circ} \mathrm{C}$ (for details, see
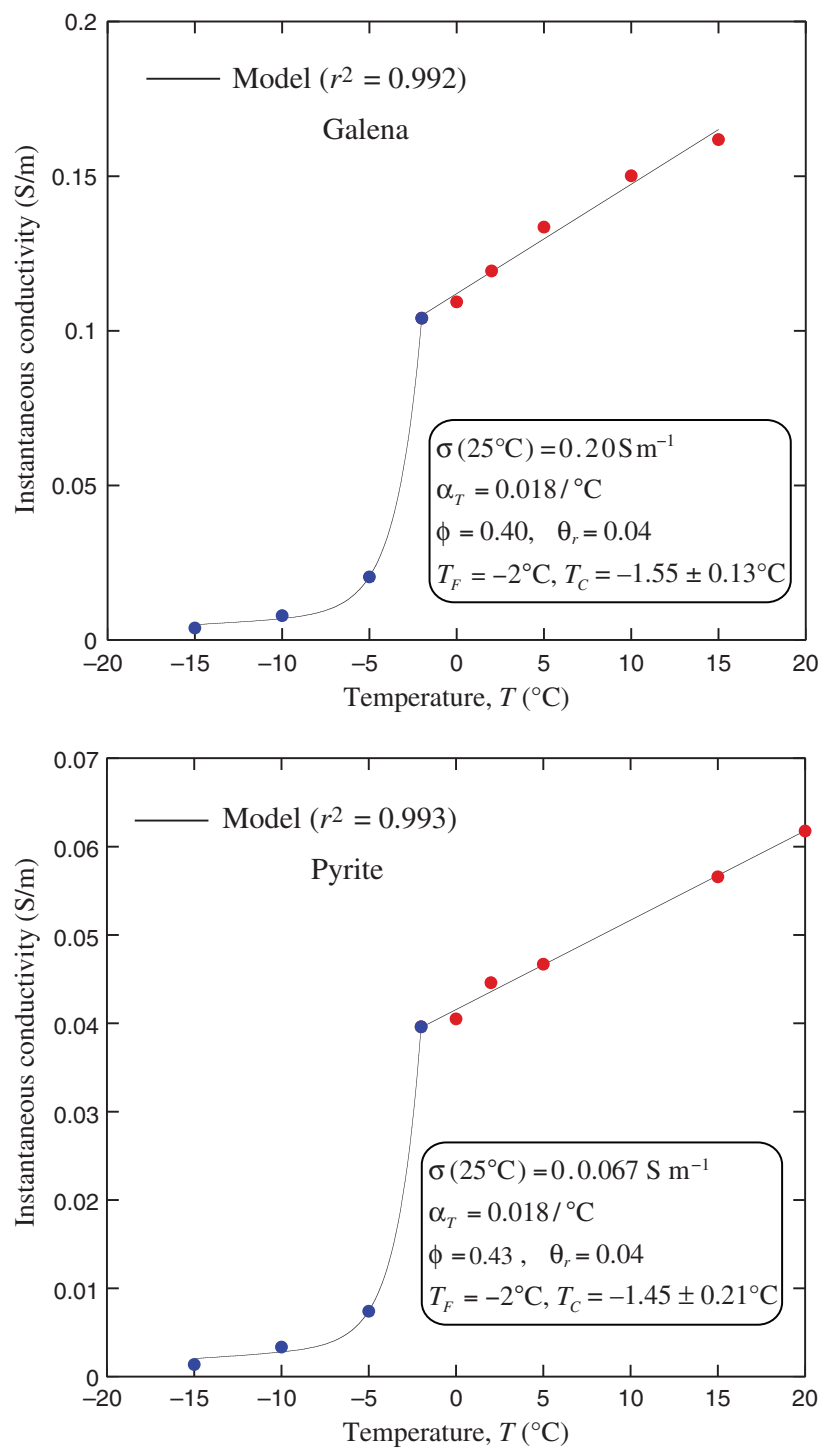

Figure 16. Evolution of the instantaneous conductivity as a function of the temperature. The data determined from the double ColeCole fit of the data on galena (experiment 2) and (experiment 6) are shown in blue below the freezing temperature and in red above the freezing temperature. 
Table 2). Below the freezing temperature, the ice in the sample is supposed to be homogeneously distributed because we wait for thermal equilibrium. The conductivity of the background material is shown in Figure 2. The typical frequency-domain spectra are shown in Figures 3, 4, 5, 6, 7, 8, and 9. For chalcopyrite and graphite (experiments 1 and 3 ), the spectra exhibit two peaks, whereas the other investigated materials show a dominant peak. For experiment 6 (graphitic-rich soil), the data show a high-frequency polarization mechanism.

The inversion of the complex conductivity spectra in terms of the Cole-Cole parameters was done with the approach discussed in Appendix A using a procedure based on a Bayesian technique. The Cole-Cole parameters for the seven experiments involving metallic particles are reported in Tables 3, 4, 5, 6, 7, 8, and 9. The two examples of the fit using a double Cole-Cole function for data exhibiting clearly a double peak are shown in Figures 10 (chalco-
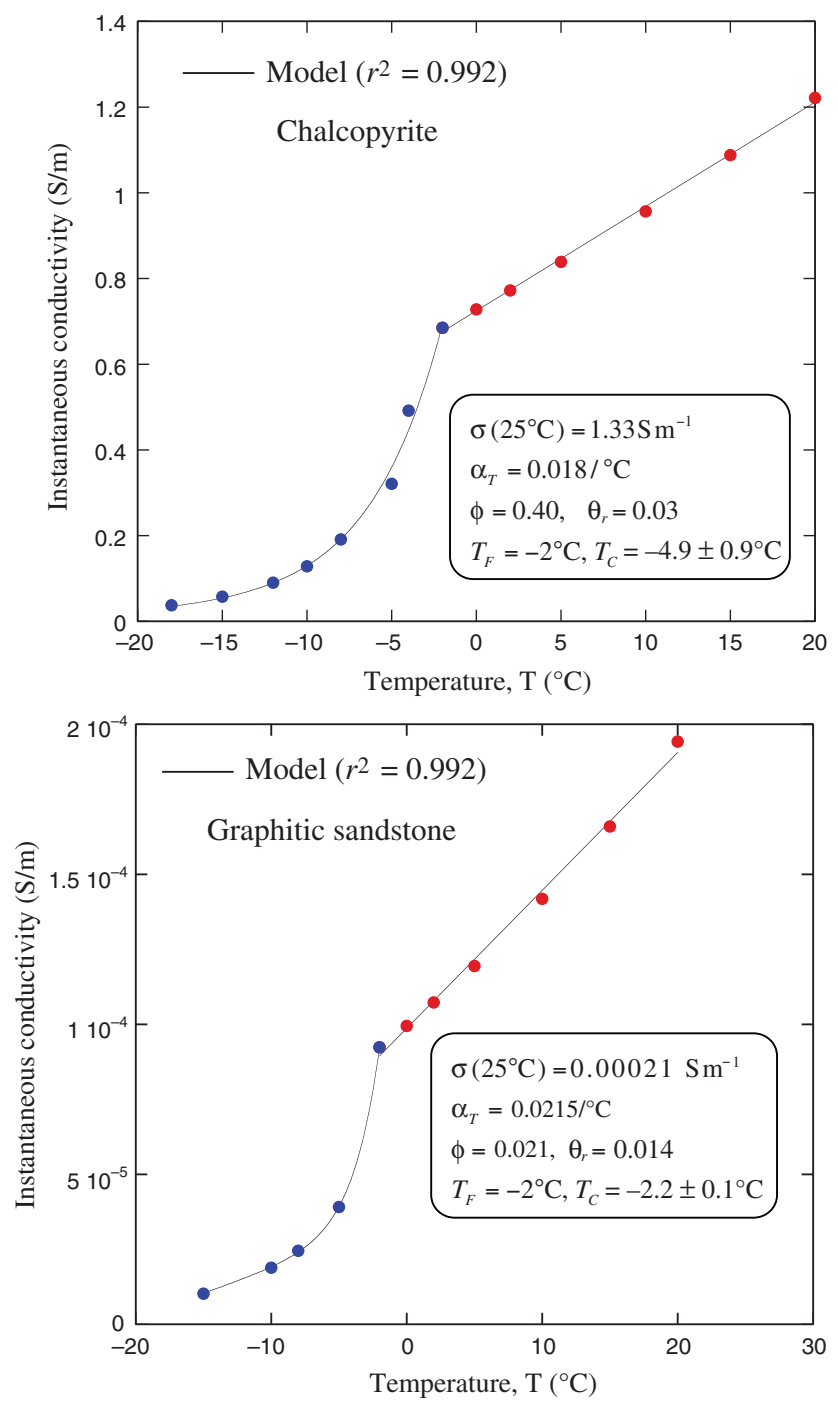

Figure 17. Evolution of the instantaneous conductivity as a function of the temperature. The data determined from the double ColeCole fit of the data on chalcopyrite (experiment 1) and graphitic sandstone (experiment 8) are shown in blue below the freezing temperature and in red above the freezing temperature. pyrite) and 11 (graphite). The dependence between the chargeability (the median value over the whole temperature range) and the volume content of the metallic particles is shown in Figure 12 and agrees fairly well with the prediction of equation 2 .

\section{RESULTS}

\section{Cole-Cole exponent}

The influence of the temperature on the Cole-Cole exponent is shown in Figures 13 and 14. In these figures, we plot the evolution of the Cole-Cole exponent against the temperature. Generally speaking, we observe no strong dependence of the Cole-Cole exponent with the temperature (with the exception of the chalcopyrite
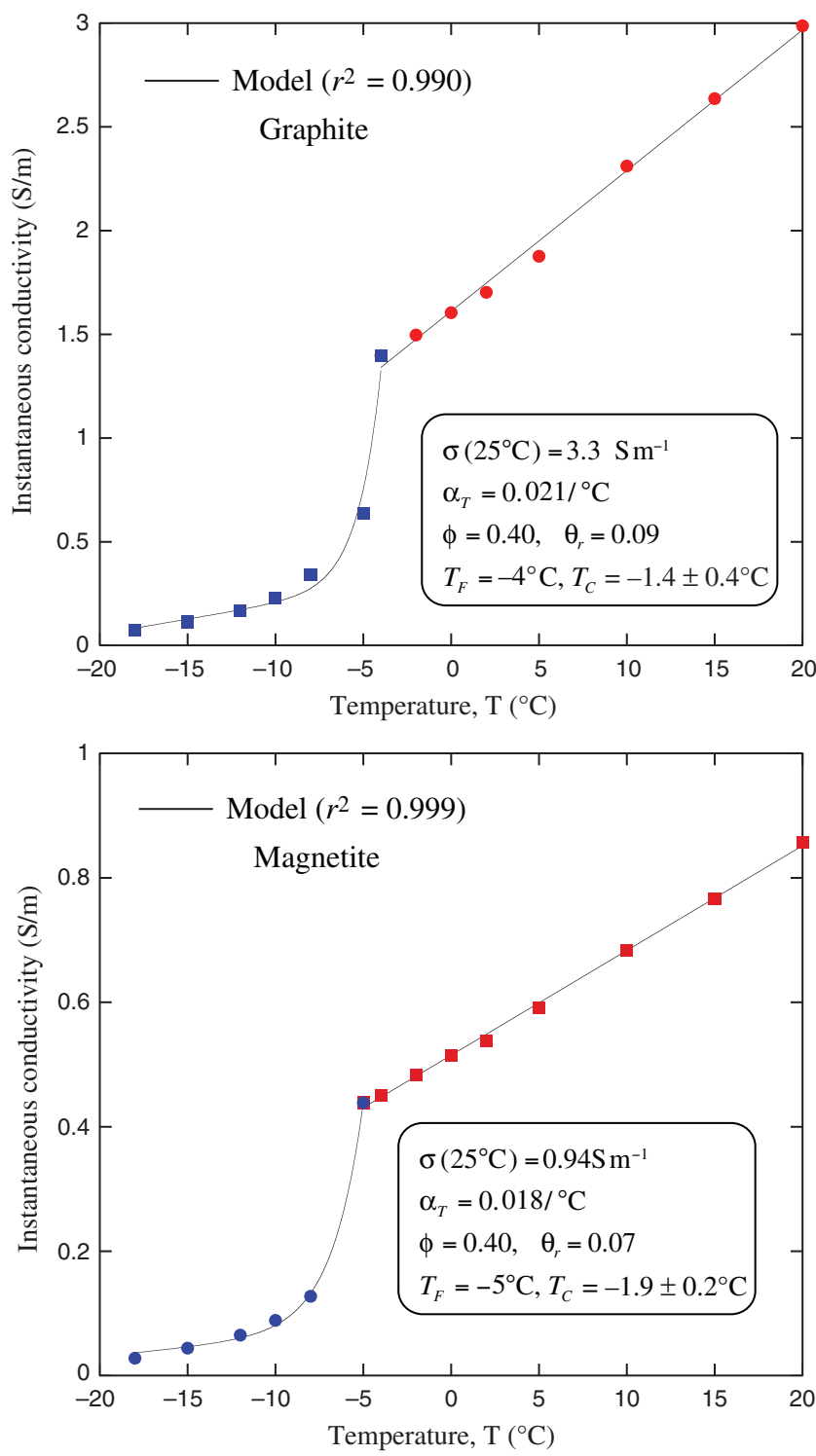

Figure 18. Evolution of the instantaneous conductivity as a function of temperature. The data determined from the double Cole-Cole fit of the data on graphite (experiment 3 ) and magnetite (experiment 4) are shown in blue below the freezing temperature and in red above the freezing temperature. 
and the graphitic soils). When the Cole-Cole exponent is temperature independent, this means in turn that all of the relaxation times forming the relaxation time probability distribution have (at least roughly) the same temperature dependence.

\section{Chargeability}

In Figure 15, we plot the chargeability of the experiments performed with metallic particles as a function of the temperature. Again, we see that at first approximation, the chargeability does not depend on the temperature. The graphitic soil and the chalcopyrite show a small increase in their chargeability below the freezing temperature. The observations are therefore generally consistent with
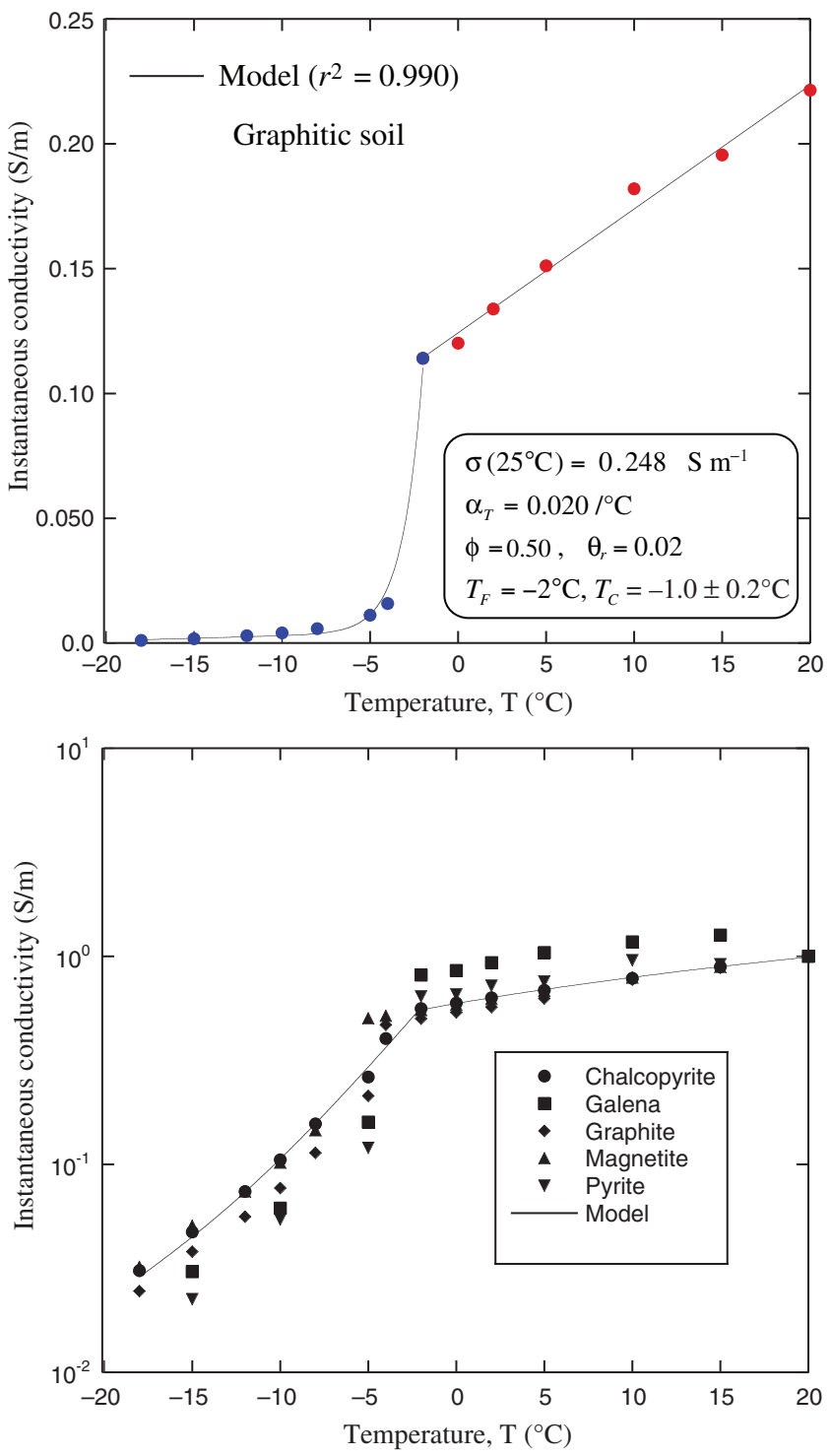

Figure 19. Evolution of the instantaneous conductivity as a function of the temperature. The data determined from the double ColeCole fit of the data on the graphitic soil (experiment 5) are shown in blue below the freezing temperature and in red above the freezing temperature. The lower figure shows all of the data with the sand as a background and normalized by the value of the instantaneous conductivity at $20^{\circ} \mathrm{C}$. our model in which the chargeability is controlled by the volumetric content of metallic particles, a property that obviously does not depend on temperature.

\section{Instantaneous conductivity}

In Figures 16, 17, 18, and 19, we plot the instantaneous conductivity of six experiments with metallic particles as a function of temperature. Here, as expected, we see a very strong effect of the freezing conditions regarding the slope of the trend between the conductivity and the temperature. This abrupt change is indeed very well observed in the data. According to our model, the change of slope is a direct effect of the change in the liquid water content and
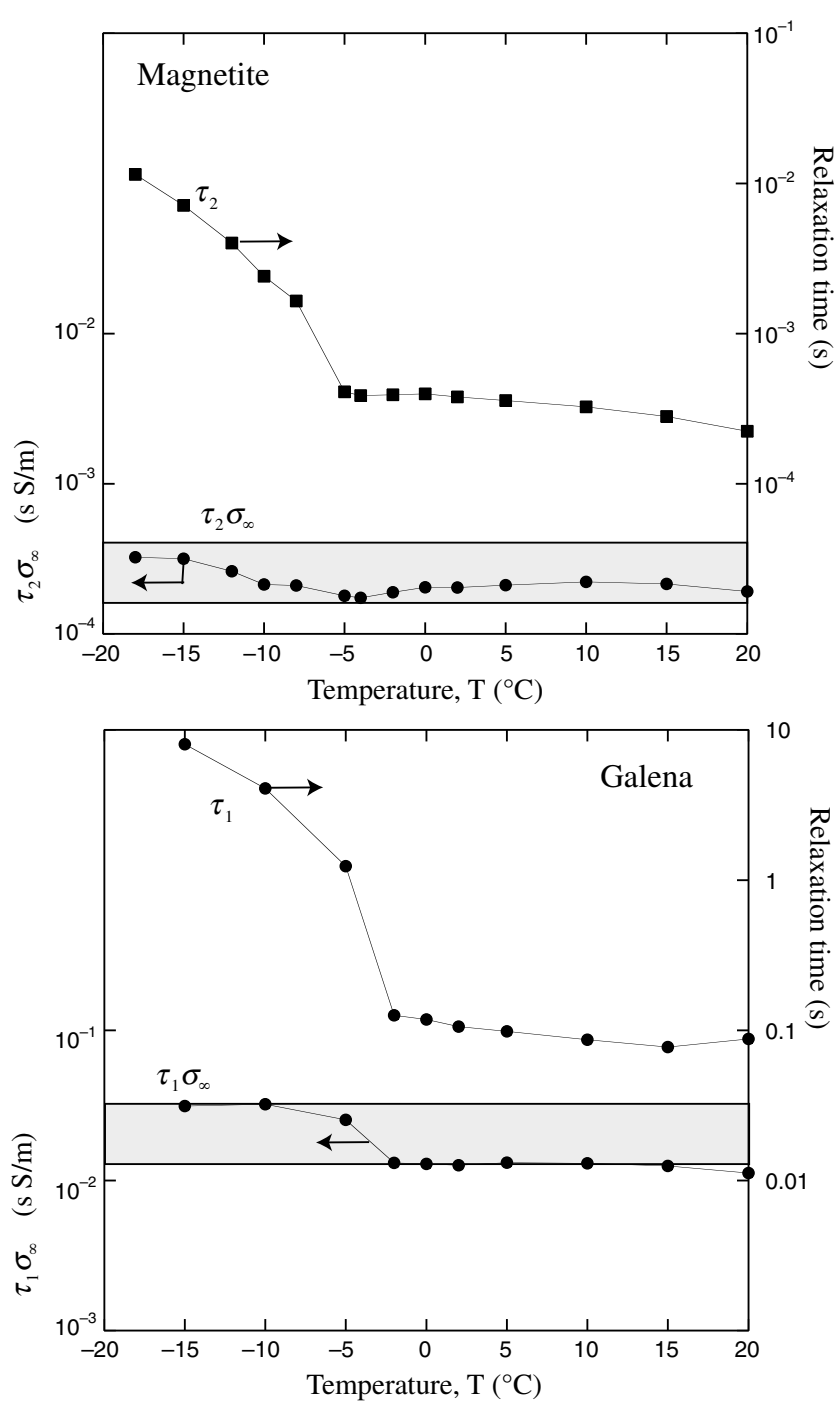

Figure 20. Evolution of relaxation times as a function of the temperature for magnetite (experiment 4) and galena (experiment 2). In this experiment, the main relaxation time is the high-frequency relaxation time. The gray band shows that the variation of the product of the instantaneous conductivity and the relaxation time is nearly constant with respect to the temperature. This indicates that the relaxation time depends on the inverse of the background conductivity. The arrows refer to the side of the graph regarding the numerical values. 
the transformation of the liquid water into ice in the pore space of the material. We see that the data are very well fitted by the model. Above $0^{\circ} \mathrm{C}$, we obtain a linear temperature dependence coefficient in the range $0.018-0.021 /{ }^{\circ} \mathrm{C}$, whereas below the freezing temperature, the exponential freezing curve properly fits the observed data. The fitting parameters are reported in the figures. Figure 16, 17, 18 and 19 also shows that all of the data corresponding to the experiments performed with the sand as background can be superposed when normalized to the (instantaneous) conductivity at $20^{\circ} \mathrm{C}$.

\section{Relaxation time}

The last parameter to investigate is the product of the instantaneous conductivity and the relaxation time as a function of the temperature. The results are shown in Figures 20, 21, and 22. We clearly observe that the relaxation time is a strong function of the
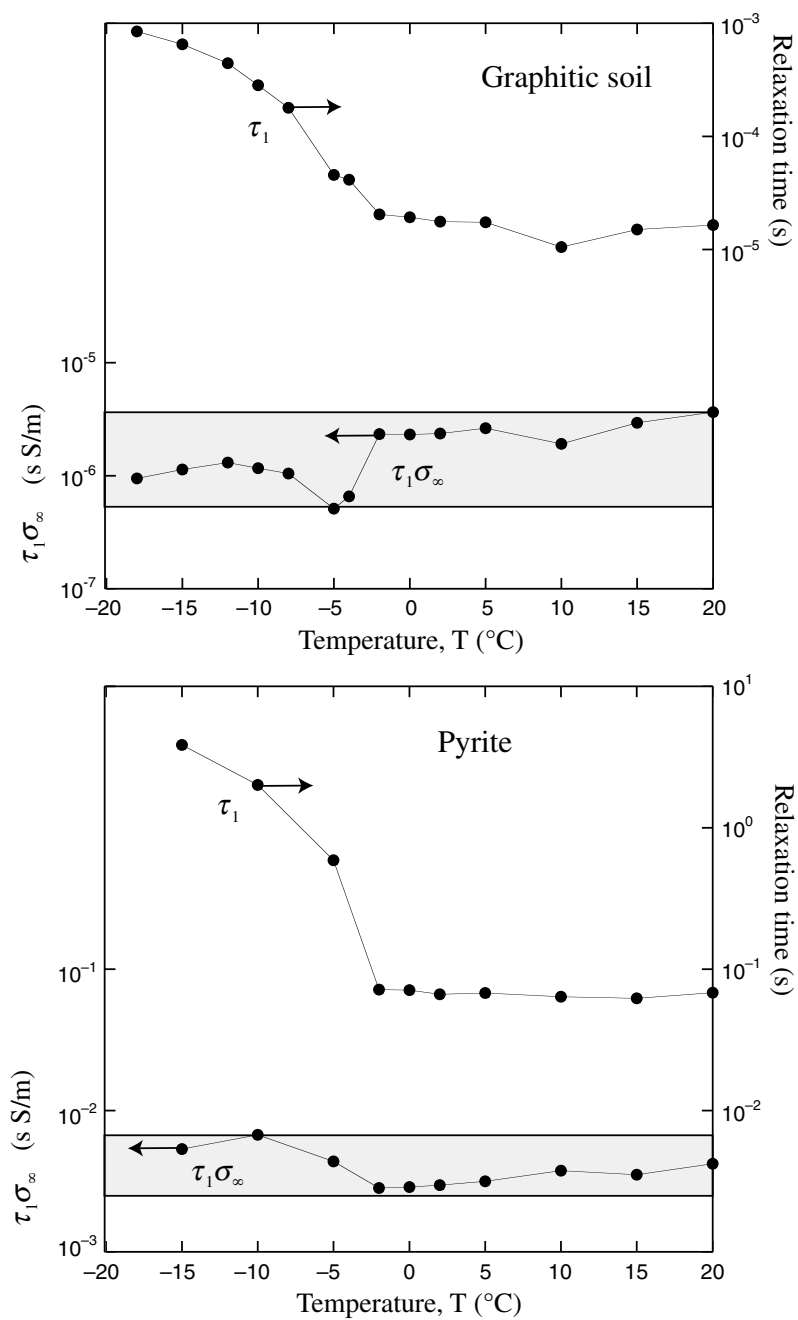

Figure 21. Evolution of the relaxation times as a function of the temperature for the graphitic soil (experiment 5) and pyrite (experiment 6). In this experiment, the main relaxation time is the low-frequency relaxation time. The gray band shows that the variation of the product of the instantaneous conductivity and the relaxation time is nearly constant with respect to the temperature. This indicates that the relaxation time depends on the inverse of the background conductivity. temperature below the freezing point. More precisely, the relaxation time is observed to strongly increase when the instantaneous conductivity (proportional to the background conductivity) of the material strongly decreases. If we calculate the product of the instantaneous conductivity and the relaxation time, we observe that this product does not change too much with the temperature (at least by comparison with the dependence of the relaxation time alone with $T$ ) as expected from our model. This implies in turn that for the temperature range investigated, the concentration of the charge carrier is temperature independent and that the relaxation time does not depend on the mobility of the charge carriers in the metallic particles. Figures 23 and 24 show that the low-frequency relaxation time is essentially inversely proportional to the instantaneous conductivity of the background. The product of these two properties depends only on the product of the grain size of the metallic particle
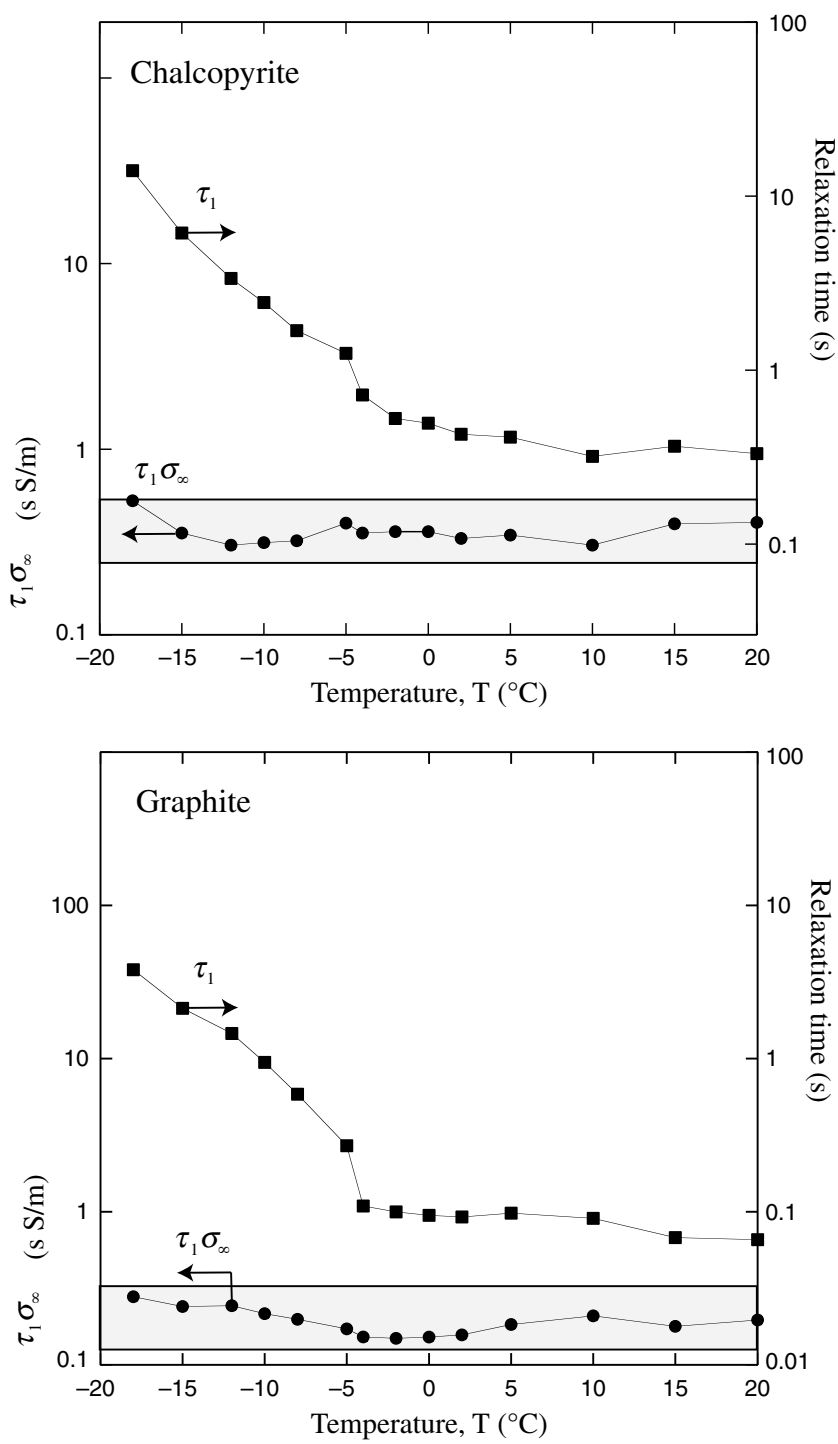

Figure 22. Evolution of the relaxation times as a function of the temperature for chalcopyrite (experiment 1) and graphite (experiment 3). The gray band shows that the variation of the product of the instantaneous conductivity and the relaxation time is nearly constant with respect to the temperature. 
and the charge concentration inside the metallic particles (see equation 25). However, this inverse relationship suffers some exceptions. For instance, the relationship between the Cole-Cole relaxation time

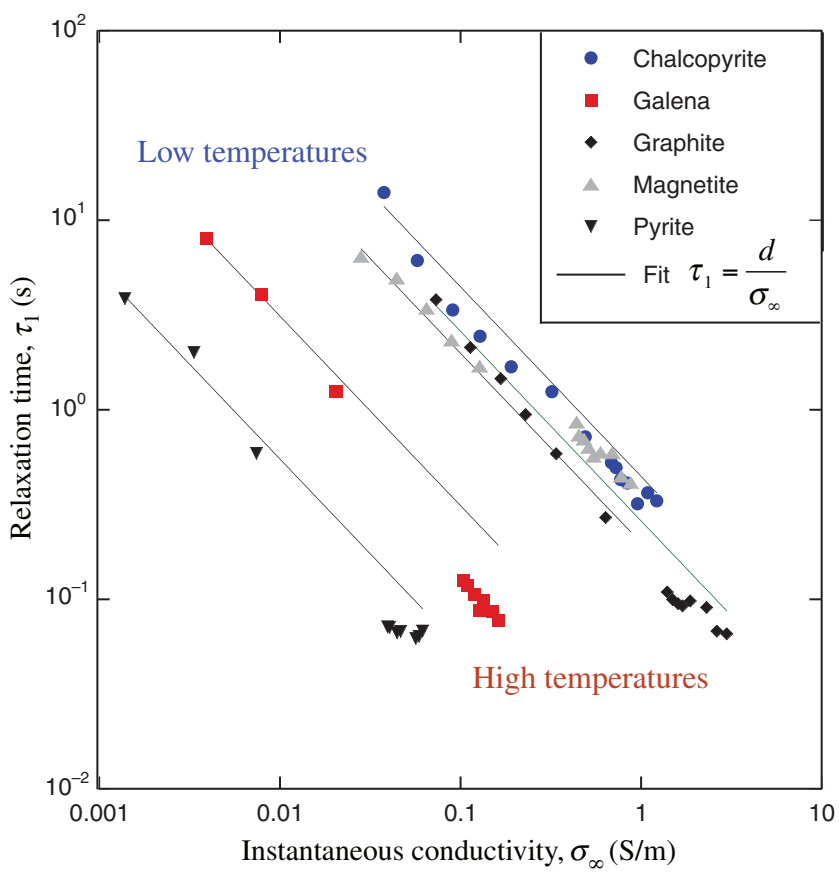

Figure 23. Relationship between the instantaneous conductivity and the low-frequency relaxation time for all of the samples with sand as the background We observe that at first approximation, the low-frequency relaxation time is inversely proportional to the instantaneous conductivity of the material. In the equation $\tau_{1}=d / \sigma_{\infty} d$ is a fitting constant for each material.

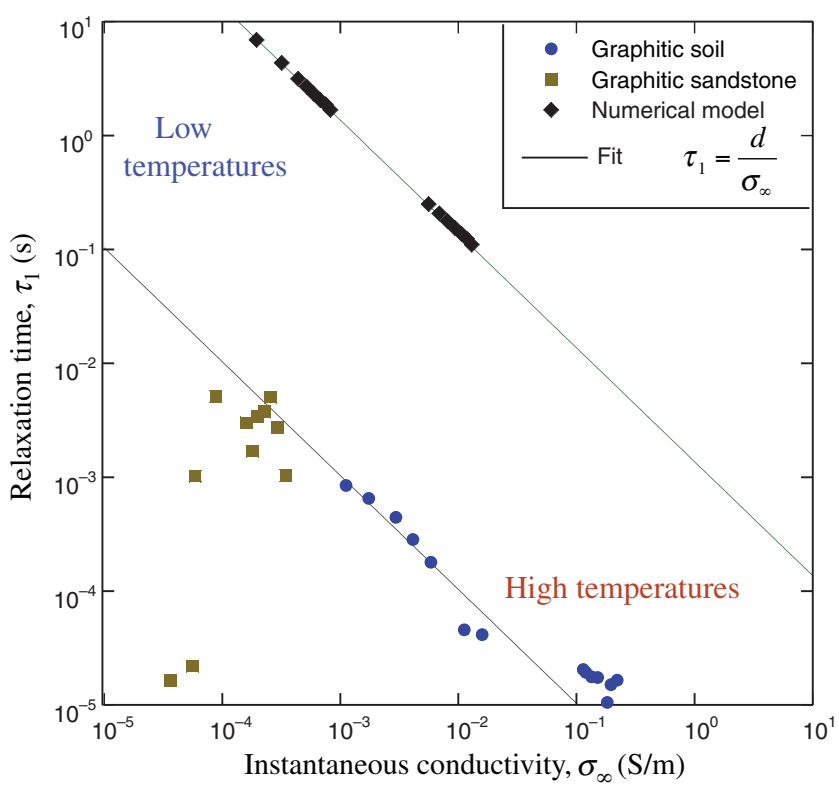

Figure 24. Relationship between the instantaneous conductivity and the low-frequency relaxation time for the graphitic soil and the graphitic sandstone from Val Thorens. We observe that at first approximation, the low-frequency relaxation time is inversely proportional to the instantaneous conductivity of the material. and the instantaneous conductivity does not hold for the graphitic sandstone.

\section{Results of the numerical simulations}

The parameters used for the numerical simulations are reported in Table 10. In Figure 24, we observe the modeling of the spectral IP response in terms of the relationship between the relaxation time and the instantaneous conductivity of the metallic grain in the porous background. In Figure 25, we represent the instantaneous conductivity and the relaxation time versus the temperature. We see that the numerical modeling is consistent with the laboratory observations in showing that the relaxation time is inversely proportional to the instantaneous conductivity of the mixture.
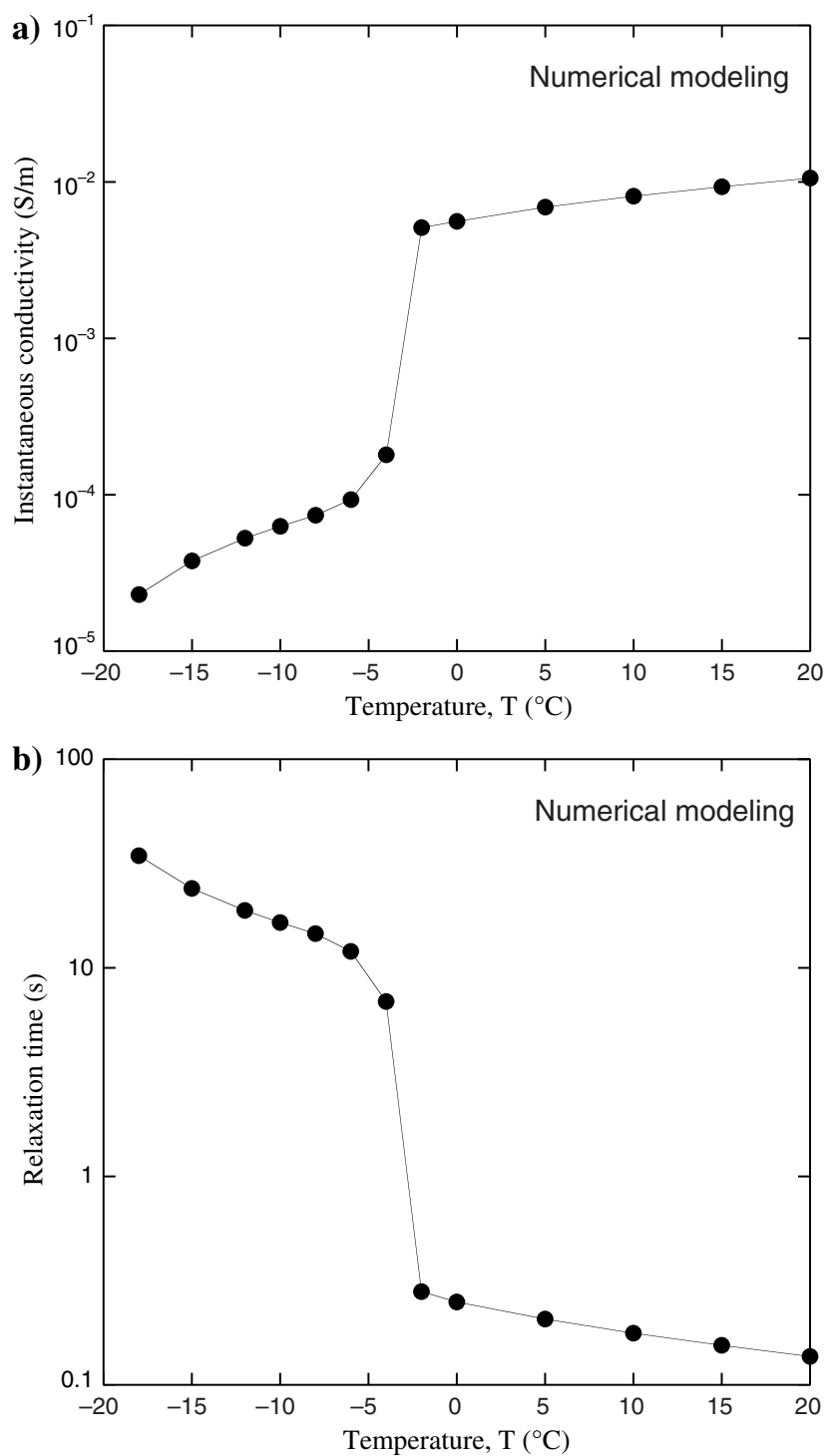

Figure 25. Results of the finite element numerical model. (a) Instantaneous conductivity versus temperature. (b) Relaxation time versus temperature. We observe that these curves very well reproduce the experimental results. 
Table 10. Parameters used for the finite-element simulation.

\begin{tabular}{lc}
\hline Parameter & Value \\
\hline$D_{(-)}$ & $1.7 \times 10^{-9} \mathrm{~m}^{2} \mathrm{~s}^{-1}$ \\
$D_{(+)}$ & $1.1 \times 10^{-9} \mathrm{~m}^{2} \mathrm{~s}^{-1}$ \\
$D_{(+)}^{m}=D_{(-)}^{m}$ & $2.9 \times 10^{-5} \mathrm{~m}^{2} \mathrm{~s}^{-1}$ \\
$C_{(+)}^{m}=C_{(-)}^{m}$ & $2.8 \times 10^{22} \mathrm{~m}^{-3}$ \\
$T_{0}$ & $298 \mathrm{~K}$ \\
$\varepsilon_{0}$ & $8.81 \times 10^{-12} \mathrm{~F} / \mathrm{m}$ \\
$\varepsilon_{S}$ & $10.9 \varepsilon_{0}$ \\
$\varepsilon_{w}$ & $80 \varepsilon_{0}$ \\
$\varphi$ & 0.40 \\
$\theta_{r}$ & 0.05 \\
$T_{F}$ & $-2^{\circ} \mathrm{C}$ \\
$T_{C}$ & $-1^{\circ} \mathrm{C}$ \\
$A$ & $500 \mu \mathrm{m}$ \\
\hline
\end{tabular}

Note: The quantity $C_{( \pm)}^{m}$ denotes the charge concentration in the semiconductor grain at equilibrium state; $D_{( \pm)}^{m}$ denotes the diffusion coefficients of the charge carriers in the metallic particle; $D_{( \pm)}$denotes the diffusion coefficients of cations and anions in the solution; and $\varepsilon_{0}, \varepsilon_{S}$, and $\varepsilon_{w}$ denote the permittivity of the free space, the permittivity of the metallic grain, and the permittivity of the electrolyte, respectively (their temperature dependence is small and neglected). The quantity $\phi$ denotes the porosity of the background, and $T_{F}$ and $T_{C}$ denote the two temperatures in the exponential freezing law (equation 26). The instantaneous conductivity of the metallic grain is $10 \mathrm{~S} \mathrm{~m}^{-1}$ (at $25^{\circ} \mathrm{C}$ ), whereas the conductivity of the solution at $25^{\circ} \mathrm{C}$ is $0.01 \mathrm{~S} \mathrm{~m}^{-1}$. The quantity $a$ denotes the diameter of the metallic particle.

\section{CONCLUSION}

New complex conductivity measurements have been performed to determine the effect of freezing on the complex conductivity spectra in the frequency range in which properties of IP dominate. These spectra could be fitted with a Cole-Cole model; thus, most of the tests look at the effect of temperature higher and lower than the freezing point on the Cole-Cole parameters. In doing so, we have modeled the relationship between the (volumetric) water content and the temperature using an exponential freezing curve. We have further assumed that the salt remains segregated in the liquid water phase below the eutectic temperature. The results and theory mostly agree with respect to four predictions. (1) The Cole-Cole exponent is temperature independent. (2) The chargeability is temperature independent. (3) Below the freezing temperature, the Cole-Cole relaxation time strongly increases when temperature decreases. The product of the instantaneous conductivity of the material (mixture) and the Cole-Cole relaxation time is essentially constant with respect to the temperature. (4) The instantaneous conductivity of the mixture depends on temperature according to the exponential freezing curve. Our experiments were performed with sand as the background to test the prediction of our model in a simple background. In the future, we could use a more realistic background to test further the predictions of the model including in crystalline rocks.

\section{ACKNOWLEDGMENTS}

We thank E. Zimmermann for his impedance meter. We also thank N. Florsch and R. Sharma for useful discussions. We thank
L. Slater, A. Hördt, an anonymous referee, and editor C. Farquharson for their very useful comments that have greatly improved the manuscript.

\section{DATA AND MATERIALS AVAILABILITY}

Data associated with this research are available and can be obtained by contacting the corresponding author.

\section{APPENDIX A}

\section{DOUBLE COLE-COLE PARAMETERIZATION}

Because several types of double Cole-Cole models have been proposed in the literature, it is important to provide a complete description of the model that we used in this paper and the rationale for this model. As discussed in the main text and for a single polarization mechanism, a single Cole-Cole complex conductivity model is written as

$$
\sigma *=\sigma_{\infty}\left(1-\frac{M}{(i \omega \tau)^{c}}\right)
$$

where $\sigma *$ denotes the complex conductivity, $\omega$ is the angular frequency, $\sigma_{\infty}$ denotes the instantaneous conductivity $(\mathrm{S} / \mathrm{m})$, and $M=\left(\sigma_{\infty}-\sigma_{0}\right) / \sigma_{\infty}$ denotes the chargeability. A generalization of this equation for $K$ distributions is given by

$$
\begin{gathered}
\sigma *=\sigma_{\infty}\left(1-\sum_{k=1}^{K} \frac{M_{k}}{1+\left(i \omega \tau_{k}\right)^{c_{k}}}\right), \\
M_{k}=\frac{\sigma_{k}^{\infty}-\sigma_{k}^{0}}{\sigma_{\infty}} .
\end{gathered}
$$

For two distinct polarization processes, we have

$$
\begin{gathered}
\sigma *=\sigma_{\infty}\left(1-\frac{M_{1}}{1+\left(i \omega \tau_{1}\right)^{c_{1}}}-\frac{M_{2}}{1+\left(i \omega \tau_{2}\right)^{c_{2}}}\right), \\
\sigma_{\infty}=\sigma_{1}^{\infty}+\sigma_{2}^{\infty}, \\
\sigma_{0}=\sigma_{1}^{0}+\sigma_{2}^{0},
\end{gathered}
$$

where $M_{1}$ and $M_{2}$ are the chargeabilities, $c_{1}$ and $c_{2}$ are the two Cole-Cole exponents (dimensionless), and $\tau_{1}$ and $\tau_{2}$ are the (relaxation) time constants (s). Indexes 1 and 2 refer to lower and higher frequency dispersions, respectively. If the global chargeability is defined by $M=\left(\sigma_{\infty}-\sigma_{0}\right) / \sigma_{\infty}$, we have

$$
M_{1}+M_{2}=\frac{\sigma_{1}^{\infty}-\sigma_{1}^{0}}{\sigma_{\infty}}+\frac{\sigma_{2}^{\infty}-\sigma_{2}^{0}}{\sigma_{\infty}}
$$




$$
M_{1}+M_{2}=\frac{\sigma_{1}^{\infty}+\sigma_{2}^{\infty}-\left(\sigma_{1}^{0}+\sigma_{2}^{0}\right)}{\sigma_{\infty}}=M,
$$

and because $0 \leq M \leq 1$, we have $0 \leq M_{1}+M_{2} \leq 1$. The two ColeCole distributions can be due to two different grain sizes. Another possibility is that the high-frequency polarization is from field-induced DL relaxations and the low-frequency polarization is from the polarization of the particle itself for large grains (see Figure 1). For small grains, the low-frequency polarization may be from the field-induced DL polarization.

The complex conductivity spectra can be inverted using this double Cole-Cole model and the nonlinear iterative method proposed by Mosegaard and Tarantola (1995), which is based on a Markov chain Monte Carlo sampling algorithm. The Bayesian approach describes the prior information that we have on the model vector, using a probability density $P(\mathbf{m})$, where $\mathbf{m}$ denotes the model vector of unknown parameters $\mathbf{m}=\left[\log \left(\sigma_{0}\right) ; M_{1} ; \operatorname{logit}\left(c_{1}\right), \log \left(\tau_{1}\right) ; M_{2}\right.$; $\left.\operatorname{logit}\left(c_{2}\right) ; \log \left(\tau_{2}\right)\right]$. Then, the algorithm combines this information with the observed data vector $\mathbf{d}_{\text {obs }}$ and with the information provided by the double Cole-Cole model, $L(\mathbf{m})$, as described in equation A-1. In Bayesian theory, the posterior probability density $\sigma(\mathbf{m})$ equals the prior probability density $P(\mathbf{m})$ times a likelihood function $L(\mathbf{m})$, which measures the fit between observed data and data predicted from the model vector $\mathbf{m}$, i.e., $\sigma(\mathbf{m})=k P(\mathbf{m}) L(\mathbf{m})$, where $k$ is a normalization constant. We describe the complex conductivity results by a vector of observed values $\mathbf{d}_{\text {obs }}$ with Gaussian experimental uncertainties. We consider the case of independent, identically distributed Gaussian uncertainties. Then, the likelihood function describing the experimental uncertainties is given by

$$
L(\mathbf{m})=k \exp \left(-\frac{S(\mathbf{m})}{s^{2}}\right),
$$

where $s^{2}$ is the total noise variance and the misfit function is given by

$$
S(\mathbf{m})=\frac{1}{2} \sum_{i=1}^{n}\left(g^{i}(\mathbf{m})-d_{\mathrm{obs}}^{i}\right)^{2}
$$

where $\mathbf{d}$ is the data vector, $g(\mathbf{m})=\rho^{*}$ is the forward-modeling function, and $s^{2}$ is the same for all data values. The acceptance probability for a perturbed model then becomes

$$
P_{\text {accept }}=\left\{\begin{array}{cl}
1 & \text { if } S\left(\mathbf{m}_{\text {new }}\right) \leq S\left(\mathbf{m}_{\text {old }}\right) \\
\exp \left(-\frac{\Delta S}{s^{2}}\right) & \text { if } S\left(\mathbf{m}_{\text {new }}\right)>S\left(\mathbf{m}_{\text {old }}\right)
\end{array},\right.
$$

where $\Delta S=S\left(\mathbf{m}_{\text {new }}\right)-S\left(\mathbf{m}_{\text {old }}\right)$. The observed data used in the inversion process were the real and imaginary parts of the complex conductivity calculated from the amplitude and phase values measured at different frequencies. We assume that the standard deviation $s$ is equal to $10 \%$ of the measured complex resistivity values (i.e., corresponding to the maximum of the experimental error). Locally, uniform law (the probability distribution is constant over an interval $[\theta 1, \theta 2]$ and vanishes elsewhere) is used to describe the prior probability density of the model parameters. The interval ranges for the Cole-Cole model parameters are $\rho_{0}=[0.01,100] \Omega \mathrm{m}, m_{1}, m_{2}, m_{3}$, $c_{1}, c_{2}$, and $c_{3}$ have the same interval $[0,1], \tau_{1}=\left[10^{-3}, 10^{1}\right] \mathrm{s}$, $\tau_{2}=\left[10^{-6}, 10^{1}\right] \mathrm{s}$, and $\tau_{3}=\left[10^{-15}, 10^{-5}\right] \mathrm{s}$. At the end of the inver- sion algorithm, we compute the root-mean-square (rms) error to quantify the fit quality:

$$
\mathrm{rms}^{2}=\frac{1}{n} \sum_{i=1}^{n}\left(\frac{g^{i}(\mathbf{m})-d_{\mathrm{obs}}^{i}}{d_{\mathrm{obs}}^{i}}\right)^{2}
$$

where $n$ denotes the number of measurements (see Tables 3-9).

\section{REFERENCES}

Abdel Aal, G. Z., E. A. Atekwana, and A. Revil, 2014, Geophysical signatures of disseminated iron minerals: A proxy for understanding subsurface biophysicochemical processes: Journal of Geophysical Research, 119, 1831-1849, doi: 10.1002/2014JG002659.

Abdulsamad, F., N. Florsch, and C. Camerlynck, 2017, Spectral induced polarization in a sandy medium containing semiconductor materials: Experimental results and numerical modelling of the polarization mechanism: Near Surface Geophysics, 15, 669-683, doi: 10.3997/1873-0604 .2017052 .

Anderson, D. M., and A. R. Tice, 1972, Predicting unfrozen water contents in frozen soils from surface area measurements: Highway Research Record, 393, 12-18.

Archie, G. E., 1942, The electrical resistivity log as an aid in determining some reservoir characteristics: Trans. AIME, 146, 54-62

Binley, A., S. Kruschwitz, D. Lesmes, and N. Kettridge, 2010, Exploiting the temperature effects on low frequency electrical spectra of sandstone: A comparison of effective diffusion path lengths: Geophysics, 75, no. 6 , A43-A46, doi: 10.1190/1.3483815.

Börner, J. H., F. Girault, M. Bhattarai, L. B. Adhikari, D. Deldicque, F. Perrier, and K. Spitzer, 2018, Anomalous complex electrical conductivity of a graphitic black schist from the Himalayas of central Nepal: Geophysical Research Letters, 45, 3984-3993, doi: 10.1029/2018GL077178.

Chu, K. T., and M. Z. Bazant, 2006, Nonlinear electrochemical relaxation around conductors: Physical Review E, 74, 011501.

Cole, K. S., and R. H. Cole, 1941, Dispersion and absorption in dielectrics: Journal of Chemical Physics, 9, 341-351, doi: 10.1063/1.1750906.

Dash, J. G., H.-Y. Fu, and J. S. Wettlaufer, 1995, The premelting of ice and its environmental consequences: Reports on Progress in Physics, 58, 115-167.

Duvillard, P. A., A. Revil, A. Soueid Ahmed, Y. Qi, A. Coperey, and L. Ravanel, 2018, Three dimensional electrical conductivity and induced polarization tomography of a rock glacier: Journal of Geophysical Research, 123, 9528-9554, doi: 10.1029/2018JB015965.

Flekkøy, E. G., 2013, A physical basis for the Cole-Cole description of electrical conductivity of mineralized porous media: Geophysics, 78, no. 5, D353-D366, doi: 10.1190/geo2012-0478.1.

Ghorbani, A., A. Revil, A. Coperey, A. Soueid Ahmed, S. Roque, M. J. Heap, H. Grandis, and F. Viveiros, 2018, Complex conductivity of volcanic rocks and the geophysical mapping of alteration in volcanoes: Journal of Volcanology and Geothermal Research, 357, 106-127, doi: 10 .1016/j.jvolgeores.2018.04.014.

Gurin, G., K. Titov, Y. Ilyin, and A. Tarasov, 2015, Induced polarization of disseminated electronically conductive minerals: A semi-empirical model: Geophysical Journal International, 200, 1555-1565.

Hobbs, P. V., 2010, Ice physics, Oxford classic texts in the physical sciences: Oxford University Press.

Kemna, A., A. Binley, G. Cassiani, E. Niederleithinger, A. Revil, L. Slater, K. H. Williams, A. Flores Orozco, F.-H. Haegel, A. Hördt, S. Kruschwitz, V. Leroux, K. Titov, and E. Zimmermann, 2012, An overview of the spectral induced polarization method for near-surface applications: Near Surface Geophysics, 10, 453-468, doi: 10.3997/1873-0604.2012027.

Leroy, P., A. Revil, A. Kemna, P. Cosenza, and A. Ghorbani, 2008, Complex conductivity of water-saturated packs of glass beads: Journal of Colloid and Interface Science, 321, 103-117, doi: 10.1016/j.jcis.2007.12.031.

Liu, W., R. Chen, H. Cai, W. Luo, and A. Revil, 2017, Correlation analysis for spread spectrum induced polarization signal processing in electromagnetically noisy environments: Geophysics, 82, no. 5, E243-E256, doi: 10 .1190/GEO2016-0109.1.

Mahan, M. K., J. D. Redman, and D. W. Strangway, 1986, Complex resistivity of synthetic sulfide bearing rocks: Geophysical Prospecting, 34, 743-768, doi: 10.1111/j.1365-2478.1986.tb00491.x.

Mao, D., A. Revil, and J. Hinton, 2016, Induced polarization response of porous media with metallic particles - Part 4: Detection of metallic and non-metallic targets in time domain induced polarization tomography: Geophysics, 81, no. 4, D359-D375, doi: 10.1190/geo2015-0480.1.

Marshall, D. J., and T. R. Madden, 1959, Induced polarization, a study of its causes: Geophysics, 24, 790-816, doi: 10.1190/1.1438659. 
Melnikov, V. P. A. M. Sneqirev, and L. L. Lyakhov, 1971, Polyarizuemosti verkhikh gorizontov tolshchi mnogoletnernerzlykh gornykh porod (Polarizability of the upper horizons of permafrost layers): Geol. Goof. (Geol. Geophys.), 7.

Misra, S., C. Torres-Verdín, A. Revil, J. Rasmus, and D. Homan, 2016a, Interfacial polarization of disseminated conductive minerals in absence of redox-active species - Part 1: Mechanistic model and validation: Geophysics, 81, no. 2, E139-E157, doi: 10.1190/GEO2015-0346.1.

Misra, S., C. Torres-Verdín, A. Revil, J. Rasmus, and D. Homan, 2016b, Interfacial polarization of disseminated conductive minerals in absence of redox-active species - Part 2: Effective complex conductivity and dielectric permittivity: Geophysics, 81, no. 2, E159-E176, doi: 10.1190/ GEO2015-0400.1.

Mosegaard, K., and A. Tarantola, 1995, Monte Carlo sampling of solutions to inverse problems: Journal of Geophysical Research, 100, 1243112447, doi: 10.1029/94JB03097.

Parkhomenko, E. I., 1967, Electrical properties of rock: Pergamon Press (English Translation).

Patchett, J. G., 1975, An investigation of shale conductivity: Presented at the SPWLA 16th Annual Logging Symposium, 40.

Pelton, W. H., S. H. Ward, P. G. Hallof, W. R. Sill, and P. H. Nelson, 1978, Mineral discrimination and removal of inductive coupling with multifrequency IP: Geophysics, 43, 588-609, doi: 10.1190/1.1440839.

Phillips, C. R., 2010, Experimental study of the induced polarization effect using Cole-Cole and GEMTIP models: M.S. thesis, University of Utah.

Potter, R. W., M. A. Clynne, and D. L. Brown, 1978, Freezing-point depression of aqueous sodium-chloride solutions: Economic Geology, 73, 284-285.

Revil, A., G. Z. Abdel Aal, E. A. Atekwana, D. Mao, and N. Florsch, 2015b, Induced polarization response of porous media with metallic particles Part 2: Comparison with a broad database of experimental data: Geophysics, 80, no. 5, D539-D552, doi: 10.1190/GEO2014-0578.1.

Revil, A., A. Coperey, D. Mao, F. Abdulsamad, A. Ghorbani, M. Rossi, and D. Gasquet, 2018, Induced polarization response of porous media with metallic particles - Part 8: Influence of temperature and salinity: Geophysics, 83, no. 6, 1-22, doi: 10.1190/geo2018-0089.1.

Revil, A., and N. Florsch, 2010, Determination of permeability from spectral induced polarization data in granular media: Geophysical Journal International, 181, 1480-1498, doi: 10.1111/j.1365-246X.2010.04573.x.

Revil, A., N. Florsch, and D. Mao, 2015a, Induced polarization response of porous media with metallic particles - Part 1: A theory for disseminated semiconductors: Geophysics, 80, no. 5, D525-D538, doi: 10.1190/ GEO2014-0577.1.

Revil, A., M. Karaoulis, T. Johnson, and A. Kemna 2012, Review: Some low-frequency electrical methods for subsurface characterization and monitoring in hydrogeology: Hydrogeology Journal, 20, 617-658, doi: 10.1007/s10040-011-0819-x.

Revil, A., 2013, Effective conductivity and permittivity of unsaturated porous materials in the frequency range $1 \mathrm{mHz}-1 \mathrm{GHz}$, Water Resources Research, 49, 306-327, doi: 10.1029/2012WR012700.

Revil, A., D. Mao, Z. Shao, M. F. Sleevi, and D. Wang, 2017b, Induced polarization response of porous media with metallic particles - Part 6:
The case of metals and semi-metals: Geophysics, 82, no. 2, E97-E110, doi: 10.1190/geo2016-0389.1.

Revil, A., M. F. Sleevi, and D. Mao, 2017a, Induced polarization response of porous media with metallic particles - Part 5: Influence of the background polarization: Geophysics, 82, no. 2, E77-E96, doi: 10.1190/ geo2016-0388.1.

Rosen, L. A., and D. A. Saville, 1991, Dielectric spectroscopy of colloidal dispersions: Comparisons between experiment and theory: Langmuir, 7, 36-42.

Schlumberger, C., 1920, Study of underground electrical prospecting: Creative Media Partners, 99.

Sidorova, M. P., and D. A. Fridrikhsberg, 1973, Study of the induced polarization of systems simulating soils during freezing, Permafrost, USSR Contribution: Second International Conference: National Academy of Sciences 893, 347-349.

Snegirev, A. M., L. L. Lyakhov, and V. P. Melnikov, 1973, Application of the method of induced polarization for studying fine-grained frozen soils, Permafrost, USSR Contribution, Second International Conference: National Academy of Sciences 893, 352-354.

Streetman, B. G., and S. K. Banerjee, 2007, Solid state electronic devices, 6th ed.: PHI Learning.

Vaudelet, P., A. Revil, M. Schmutz, M. Franceschi, and P. Bégassat, 2011, Changes in induced polarization associated with the sorption of sodium, lead, and zinc on silica sands: Journal of Colloid and Interface Science, 360, 739-752.

Veeken, P, P. Legeydo, Y. Davidenko, E. Kudryavceva, S. Ivanov, and A Chuvaev, 2009, Benefits of the induced polarization geo-electric method to hydrocarbon exploration: Geophysics, 74, no. 2, B47-B59, doi: 10 $.1190 / 1.3076607$.

Vinegar, H., and M. Waxman, 1984, Induced polarization of shaly sands: Geophysics, 49, 1267-1287, doi: 10.1190/1.1441755.

Wong, J., 1979, An electrochemical model of the induced-polarization phenomenon in disseminated sulfide ores: Geophysics, 44, 1245-1265, doi: 10.1190/1.1441005

Wong, J., and D. Strangway, 1981, Induced polarization in disseminated sulfide ores containing elongated mineralization: Geophysics, 46, 1258-1268, doi: $10.1190 / 1.1441264$.

Zimmermann, E., J. Berwix, W. Glaas, H. Meier, H. M. Münch, and A. Kemna, 2007, ZEL-SIP04-V02: User manual: Forschungszentrum Jülich $\mathrm{GmbH}$.

Zisser, N., A. Kemna, and G. Nover, 2010, Dependence of spectral induced polarization response of sandstone on temperature and its relevance to permeability estimation: Journal of Geophysical Research, 115, B09214, doi: 10.1029/2010JB007526.

Zukoski, C. F., and D. A. Saville, 1986a, The interpretation of electrokinetic measurements using a dynamic model of the Stern layer -1 : The dynamic model: Journal of Colloid and Interface Science, 114, 32-44.

Zukoski, C. F., and D. A. Saville, 1986b, The Interpretation of electrokinetic measurements using a dynamic model of the Stern layer - 2: Comparisons between theory and experiments: Journal of Colloid and Interface Science, 114, 45-53. 